\title{
Preclinical investigation of folate receptor-targeted nanoparticles for photodynamic therapy of malignant pleural mesothelioma
}

\author{
TATSUYA KATO ${ }^{1,2^{*}}$, CHENG S. JIN $^{3-5^{*}}$, DAIYOON LEE ${ }^{1}$, HIDEKI UJIIE $^{1}$, KOSUKE FUJINO $^{1}$, HSIN-PEI HU ${ }^{1}$, \\ HIRONOBU WADA ${ }^{1}$, LICUN WU ${ }^{1}$, JUAN CHEN $^{6}$, ROBER A. WEERSINK $^{5,7}$, HIROMI KANNO $^{8}$, \\ YUTAKA HATANAKA $^{8}$, KANAKO C. HATANAKA ${ }^{8}$, KICHIZO KAGA $^{2}$, YOSHIRO MATSUI ${ }^{2}$, \\ YOSHIHIRO MATSUNO ${ }^{8}$, MARC DE PERROT ${ }^{1}$, BRIAN C. WILSON ${ }^{6,7}$, \\ ${\text { GANG } \text { ZHENG }^{3-7,9} \text { and KAZUHIRO YASUFUKU }}^{1}$
}

\begin{abstract}
${ }^{1}$ Division of Thoracic Surgery, Toronto General Hospital, University Health Network, Toronto, ON M5G 2C4, Canada;
${ }^{2}$ Department of Cardiovascular and Thoracic Surgery, Hokkaido University Graduate School of Medicine, Sapporo, Hokkaido 060-8638, Japan; ${ }^{3}$ Graduate Department of Pharmaceutical Sciences, Leslie Dan Faculty of Pharmacy, University of Toronto, Toronto, ON M5S 3M2; ${ }^{4}$ Institute of Biomaterials and Biomedical Engineering,

University of Toronto, Toronto, ON M5S 3G9; ${ }^{5}$ Guided Therapeutics, TECHNA Institute, University Health Network, Toronto, ON M5G 1L5; ${ }^{6}$ Department of Medical Biophysics, University of Toronto, Toronto, ON M5G 1L7;

${ }^{7}$ Radiation Medicine Program, Princess Margaret Cancer Centre, University Health Network, Toronto, ON M5G 2M9, Canada; ${ }^{8}$ Department of Surgical Pathology, Hokkaido University Hospital, Sapporo, Hokkaido 060-8648, Japan; ${ }^{9}$ DLVR Therapeutics Inc. and University Health Network, Toronto, ON M5G 0A3, Canada
\end{abstract}

Received February 7, 2018; Accepted August 1, 2018

DOI: $10.3892 /$ ijo.2018.4555

\begin{abstract}
Photodynamic therapy (PDT) following lungsparing extended pleurectomy for malignant pleural mesothelioma (MPM) has been investigated as a potential means to kill residual microscopic cells. High expression levels of folate receptor 1 (FOLR1) have been reported in MPM; therefore, targeting FOLR1 has been considered a novel potential strategy. The present study developed FOLR1-targeting porphyrin-lipid nanoparticles (folate-porphysomes, FP) for the treatment of PDT. Furthermore, inhibition of activated epidermal growth factor (EGFR)-associated survival pathways enhance PDT efficacy. In the present study, these approaches were combined; FP-based PDT was used together with an EGFR-tyrosine kinase inhibitor (EGFR-TKI). The frequency of FOLR1 and EGFR expression in MPM was analyzed using tissue microarrays. Confocal microscopy and a cell viability assay were performed to confirm the specificity
\end{abstract}

Correspondence to: Dr Kazuhiro Yasufuku, Division of Thoracic Surgery, Toronto General Hospital, University Health Network, 200 Elizabeth Street, 9N-957, Toronto, ON M5G 2C4, Canada E-mail: kazuhiro.yasufuku@uhn.ca

*Contributed equally

Key words: photodynamic therapy, malignant pleural mesothelioma, folate receptor 1, porphysome, epidermal growth factor, EGFRtyrosine kinase inhibitors of FOLR1-targeting cellular uptake and photocytotoxicity in vitro. In vivo fluorescence activation and therapeutic efficacy were subsequently examined. The effects of EGFR-TKI were also assessed in vitro. The in vivo combined antitumor effect of EGFR-TKI and FP-PDT was then evaluated. The results revealed that FOLR1 and EGFR were expressed in 79 and $89 \%$ of MPM samples, respectively. In addition, intracellular uptake of FP corresponded well with FOLR1 expression. When MPM cells were incubated with FP and then irradiated at $671 \mathrm{~nm}$, there was significant in vitro cell death, which was inhibited in the presence of free folic acid, thus suggesting the specificity of FPs. FOLR1 targeting resulted in disassembly of the porphysomes and subsequent fluorescence activation in intrathoracic disseminated MPM tumors, as demonstrated by ex vivo tissue imaging. FP-PDT resulted in significant cellular damage and apoptosis in vivo. Furthermore, the combination of pretreatment with EGFR-TKI and FP-PDT induced a marked improvement of treatment responses. In conclusion, FP-based PDT induced selective destruction of MPM cells based on FOLR1 targeting, and pretreatment with EGFR-TKI further enhanced the therapeutic response.

\section{Introduction}

Malignant pleural mesothelioma (MPM) is a relatively rare form of cancer of the chest cavity lining, which is difficult to control (1). There have been an increasing number of new cases of MPM globally since the 1960s, with $\sim 2,000$ new cases diagnosed per year in the United States (2). This progressive increase has been attributed to the increased use of asbestos, and exposure to its fibers, which can escape from the lung into 
the pleural cavity following inhalation, causing chronic and malignant transformation (3). The prognosis for patients with MPM remains poor, despite advances in medical technology and treatment modalities. Depending on the histological subtype (epithelioid, sarcomatoid or biphasic), the median life expectancy is only 8-18 months from diagnosis $(4,5)$. Current treatments are limited to either a multimodal strategy involving surgery plus chemotherapy and/or radiotherapy, or palliative chemotherapy (6). For eligible patients with resectable disease, surgery improves survival; either extrapleural pneumonectomy (EPP) or lung-sparing extended pleurectomy/ decortication (EPD) are used to remove all macroscopic nodules, alongside chemotherapy or radiotherapy to target residual microscopic disease (7). However, even with the use of aggressive multimodal treatment, the majority of patients have local recurrence, yet little is currently known about the precise pattern of relapse (8-11). Therefore, other means to eliminate microscopic disease following surgery are urgently required.

Several groups are exploring novel intrapleural therapies, including immunotherapy, gene therapy and cisplatin-based chemotherapy $(12,13)$. In line with these novel modalities, intraoperative photodynamic therapy (PDT) has recently been reported as a potential therapeutic strategy for this purpose $(14,15)$. Effective PDT requires a light-absorbing compound (photosensitizer), light at a specific wavelength to activate the photosensitizer and, for most photosensitizers, oxygen (16). The activated photosensitizer generates reactive singlet oxygen species as the primary cytotoxic agent to initiate cell death, often via apoptosis (17). At present, a few photosensitizers have been clinically approved for cancer therapy, including porfimer sodium (Photofrin ${ }^{\circledR}$ ) in the USA and m-tetrahydroxyphenylchlorin $\left(\right.$ Foscan $\left.^{\circledR}\right)$ in Europe. Photofrin, which is a multi-component derivative of hematoporphyrin, was the first photosensitizer to be evaluated for intrapleural PDT following surgery (18); it involves systemic (intravenous, i.v.) administration followed by red light delivery to irradiate the pleural cavity. Although the feasibility of this approach has been demonstrated, fatal toxicities have been noted in previous studies $(18,19)$. Similarly, Foscan-PDT may cause severe toxicity and even mortality $(20,21)$. Compiled data from 10 trials exhibited an overall mortality rate of $4.9 \%$ with Photofrin and $13.3 \%$ for Foscan, with morbidities of 38 and $70 \%$, respectively (22). Neither of these otherwise potent photosensitizers possesses marked tumor selectivity; therefore, treatment is limited by normal-tissue phototoxicity.

Porphysomes are liposome-mimicking nanoparticles ( $\sim 100 \mathrm{~nm}$ diameter) that self-assemble from porphyrin-phospholipid conjugates (23). They have an extremely high porphyrin density (>80,000 per nanoparticle), so that PDT efficacy and associated fluorescence are highly quenched in solution (24). However, these are restored upon disassembly of the nanoparticles following cellular internalization. In our previous study, folic acid was integrated into the porphysome formulation at 1 mole $\%$ to enable targeting of folate receptors (folate-porphysomes, FPs), in order to actively target tumor cells that had overexpressed folate receptors (25). FPs initially accumulate in the tumor interstitial space through the enhanced permeation and retention (EPR) effect and are then taken up by tumor cells through folate receptor 1 (FOLR1)-mediated active transport.
Both fluorescence and the resulting PDT efficacy were demonstrated in a mouse subcutaneous tumor model (25). High expression levels of FOLR1 have been clinically reported in $39-72 \%$ of MPM cases $(26,27)$. It was hypothesized that a nanostructure-based photosensitizer may be advantageous to obtain significant tumor-specific accumulation in MPM, and to minimize toxicity to surrounding normal tissues in the pleural cavity (28). PDT, enabled by folate receptor targeting of porphysomes, has recently been evaluated by the University Health Network (Toronto, ON, Canada) as a promising novel strategy to treat various types of cancer $(23,24)$. In the present study, the targeting efficiency of FPs towards MPM cells was determined in vitro and in vivo, based on fluorescence imaging, and the FP-PDT efficacy was also measured in vitro and in vivo in a mouse subcutaneous MPM tumor model.

Another aspect of PDT is that it has been reported to stimulate survival pathways via the nuclear accumulation of activated epidermal growth factor receptor (EGFR) (29). Notably, growing tumors stimulate neovascularization through the secretion of various proangiogenic growth factors, including vascular endothelial growth factor and EGFR (30). Therefore, deactivating these pathways using EGFR-tyrosine kinase inhibitors (EGFR-TKIs) may potentially enhance PDT efficacy (29). Combinations of PDT with small molecules or anti-EGFR antibodies have been reported to increase the cytotoxicity of PDT in non-small cell lung cancer, nasopharyngeal carcinoma and bladder carcinoma (31-34). Furthermore, EGFR has been reported, using immunohistochemistry, to be overexpressed in 44-97\% of patients with MPM, with high variability across studies (35-39). Therefore, the present study initially evaluated the expression levels of FOLR1 and EGFR in MPM clinical samples, as confirmation of their overexpression, using histological subset analysis. It was further hypothesized that blocking EGFR pathways by EGFR-TKI alongside FP-PDT could achieve a greater response in MPM with fewer side effects; therefore, the present study evaluated the expression levels of EGFR, and the efficacy of combined EGFR-TKIs and FP-PDT in vivo.

\section{Materials and methods}

MPM clinical tissue samples. A total of 156 MPM tissue samples (EPP, $n=22$; pleural biopsy, $n=26$; recurrent tumor resection, $n=3$; radical pleurectomy, $n=1$ ) were obtained from 52 patients undergoing surgery at Hokkaido University Hospital (Sapporo, Japan) and affiliated hospitals (Sapporo Minami-Sanjyo Hospital, Sapporo, Japan and Kinikyo-Chuo Hospital, Sapporo, Japan) between February 1990 and April 2012. All specimens were fixed in $10 \%$ formalin for 3-5 days at room temperature and embedded in paraffin. Three tissue cores ( $1 \mathrm{~mm}$ diameter) taken from each tumor block were placed into recipient paraffin blocks using a tissue microarrayer (JF-4; Sakura Finetek Japan, Tokyo, Japan). Tissue areas for sampling were selected based on visual alignment of paraffin-embedded blocks with the corresponding hematoxylin and eosin (H\&E)-stained sections on slides. $\mathrm{H} \&$ E staining was performed using an automated slide stainer and coverslipper (Tissue-Tek Prisma Plus; Sakura Finetek Japan). All tumors were histologically reviewed by two experienced pathologists $(\mathrm{HK}$ and $\mathrm{KCH})$. Clinical information 
of the patients was obtained from the medical records. The protocol was approved by the Independent Clinical Research Review Board of Hokkaido University Hospital [approval no. 012-0136]. All patients provided written informed consent prior to surgery. The median age at the time of diagnosis was 65.6 years (range, $35-80$ years) and $92.3 \%$ of the patients were men. Among the 52 MPM cases, 33 were of the epithelioid type $(63.5 \%), 13$ were biphasic $(25.0 \%)$, five were sarcomatoid $(9.6 \%)$ and one was desmoplastic (1.9\%) (Table I). Histological classification of tumors and stage were performed according to the Union for International Cancer Control pathological tumor/node/metastasis classification criteria (40).

MPM cell lines. Murine (AE17, AE17-sOVA, AK7, AB12 and RN5) and human (H28, H226, H2052 and H2452) MPM cells lines were used, as well as a control human adult normal mesothelial cell line (MES-F) (41). A lung large cell carcinoma cell line (H460) that overexpresses folate receptor was used as a positive control. Mixed cancer type KB cell line (42) was also used as a FOLR1-positive control, as in our previous study (25). The human MPM cell lines (H28, H226, H2052 and H2452) were purchased from American Type Culture Collection (Manassas, VA, USA). AB12 was donated by Dr. Jay Kolls (University of Pittsburgh, Pittsburgh, PA, USA). AE17 cells were obtained from the European Collection of Authenticated Cell Cultures (Salisbury, UK). AE17-sOVA cells were developed by stably transfecting the AE17 parental cell line with secretory ovalbumin (sOVA) $(43,44)$. The AK7 cell line (45) was kindly provided by Dr Steven Albelda (University of Pennsylvania, Philadelphia, PA, USA) and Dr Delia Nelson (University of Western Australia, Crawley, WA, Australia). The RN5 cell line was developed in collaboration with the University of Fribourg (Fribourg, Switzerland) (46). MES-F was purchased from Zen-Bio, Inc. (Research Triangle Park, NC, USA) and was grown in mesothelial cell growth medium (Zen-Bio, Inc.). KB and H460 cells were provided by Dr Ming-Sound Tsao (University of Toronto, Toronto, ON, Canada). All cells, with the exception of the MES-F cell line, were grown as monolayers in RPMI-1640 medium (SigmaAldrich; Merck KGaA, Darmstadt, Germany) supplemented with $10 \%$ fetal bovine serum (FBS, Gibco; Thermo Fisher Scientific, Inc., Waltham, MA, USA). All cells were maintained at $37^{\circ} \mathrm{C}$ in a humidified atmosphere containing $5 \% \mathrm{CO}_{2}$.

Western blotting for in vitro FOLR1 expression. After cells were grown to $>80 \%$ confluence, they were lysed with radioimmunoprecipitation assay buffer $(\mathrm{pH} 7.5$; $50 \mathrm{mmol} / \mathrm{l}$ Tris-HCl, $1 \mathrm{mmol} / 1$ EDTA, $100 \mathrm{mmol} / 1 \mathrm{NaCl}$, $1 \%$ Triton $\mathrm{X}-100)$ containing protease inhibitors $(20 \mu \mathrm{mol} / 1$ leupeptin, $0.8 \mu \mathrm{mol} / 1$ aprotinin, $10 \mu \mathrm{mol} / 1$ pepstatin and 1.25 $\mathrm{mmol} / \mathrm{l}$ phenylmethylsulfonyl fluoride). Cell lysates were maintained at $4^{\circ} \mathrm{C}$ for $15 \mathrm{~min}$ and were then centrifuged at $14,000 \mathrm{x} \mathrm{g}$ for $15 \mathrm{~min}$ at $4^{\circ} \mathrm{C}$. The total protein concentration in the supernatant was quantified using a bicinchoninic acid protein assay reagent kit (Bio-Rad Laboratories, Inc., Mississauga, ON, Canada). Protein (10 $\mu \mathrm{g} / \mathrm{lane})$ was loaded for each cell line and was separated by $10 \%$ SDS-PAGE at $100 \mathrm{~V}$ for $90 \mathrm{~min}$. Proteins were then transferred onto a nitrocellulose membrane using a Miniprotein III electro-blotter (Bio-Rad Laboratories, Inc.). The membranes were blocked in 5\%
Table I. Patients and tumor characteristics $(n=52)$.

\begin{tabular}{lrl}
\hline Variables & \multicolumn{2}{c}{ Values } \\
\hline Sex, male/female (\%) & $48 / 4(92.3 / 7.7)$ \\
Mean age, years (range) & $65.6(35-80)$ \\
Histology & & \\
Epithelioid, n (\%) & 33 & $(63.5)$ \\
Biphasic, n (\%) & 13 & $(25.0)$ \\
Sarcomatoid, n (\%) & 5 & $(9.6 \%)$ \\
Desmoplastic, n (\%) & 1 & $(1.9 \%)$ \\
Surgical procedure & & \\
Extrapleural pneumonectomy, n (\%) & 22 & $(42.3)$ \\
Pleural biopsy, n (\%) & 26 & $(50.0)$ \\
Recurrent tumor resection, n (\%) & 3 & $(5.8)$ \\
Radical pleurectomy, n $(\%)$ & 1 & $(1.9)$ \\
Total & 52 & \\
\end{tabular}

skimmed milk-Tris-buffered saline (TBS) containing $0.1 \%$ Tween-20 (TBST) for $2 \mathrm{~h}$ at $4^{\circ} \mathrm{C}$, after which, the immunoblots were washed in TBST and probed overnight at $4^{\circ} \mathrm{C}$ with antiFOLR1 primary antibody [EPR4708(2)] (cat. no. ab125030; Abcam, Cambridge, MA, USA) at a 1:1,000 dilution. Membranes were washed and were then incubated for $1 \mathrm{~h}$ at room temperature with an anti-rabbit horseradish peroxidase (HRP)-conjugated secondary antibody at a 1:2,000 dilution (cat. no. A00098; GenScript Biotech Corporation, Pascataway, NJ, USA). Bound antibodies were detected using a Gel Logic 2200 Imaging system (Kodak, Rochester, NY, USA) following treatment with Clarity Western enhanced chemiluminescence reagent (Bio-Rad Laboratories, Inc.). The membranes were then stripped and immunoblotted with a mouse monoclonal antibody against $\beta$-actin (cat. no. A5441, 1:5,000; SigmaAldrich; Merck KGaA) and anti-mouse HRP-conjugated secondary antibody (cat. no. A00160; GenScript Biotech Corporation) at a 1:2,000 dilution.

Porphysome synthesis. Non-targeted (regular) porphysomes and FPs were synthesized according to a previously described protocol $(23,25)$. The lipid film for non-targeted porphysomes consisted of 55 mole\% pyropheophorbide-lipid, 40 mole $\%$ cholesterol (Avanti Polar Lipids, Avanti, AL, USA) and 5 mole\% distearoyl-sn-glycero-3-phosphoethanolamineN-methoxy (polyethene glycol) (PEG2000-DSPE; Avanti Polar Lipids). For FPs, 1 mole\% 1, 2-distearoyl-sn-glycero3-phosphoethanolamine-folate (polyethylene glycol) (Folate-PEG2000-DSPE; Avanti Polar Lipids) was added to the formulation, together with 4 mole\% PEG2000-DSPE, 55 mole\% porphyrinlipid (pyropheophorbide-lipid) and 40 mole\% cholesterol (Avanti Polar Lipids). The lipid films were dried under a gentle stream of nitrogen gas, followed by $1 \mathrm{~h}$ under a vacuum to remove the remaining solvent. The dried lipid films were stored at $20^{\circ} \mathrm{C}$ under argon gas until synthesis. To obtain fresh porphysomes for each experiment, the lipid films were rehydrated with $1.0 \mathrm{ml}$ PBS $\left(150 \times 10^{-3} \mathrm{M}, \mathrm{pH} 7.5\right)$ and extruded 10 times under high $\mathrm{N}_{2}$ pressure through a polycarbonate membrane (pore size, $100 \mathrm{~nm}$ ), after which, they 
were kept sterile at $4^{\circ} \mathrm{C}$. The nanoparticle sizes were measured using dynamic light scattering (ZS90 Nanosizer; Malvern Instruments, Malvern, UK) and the porphyrin concentration was determined by UV-Vis absorption spectrometry (Varian Medical Systems, Inc., Palo Alto, CA, USA).

Cellular uptake and fluorescence activation of porphysomes. Confocal fluorescence microscopy was used to determine the cellular internalization of non-targeted porphysomes and FPs. Upon reaching $>80 \%$ confluence, $10^{5}$ cells were seeded in a 2-well chamber slide (Lab-Tek ${ }^{\mathrm{TM}}$; Sigma-Aldrich; Merck $\mathrm{KGaA}$ ) and were incubated for $24 \mathrm{~h}$ at $37^{\circ} \mathrm{C}$. The medium was then replaced with fresh medium containing non-targeted porphysomes $\left(5 \times 10^{-6} \mathrm{M}\right)$, FPs $\left(5 \times 10^{-6} \mathrm{M}\right)$ or FPs $\left(5 \times 10^{-6} \mathrm{M}\right)$

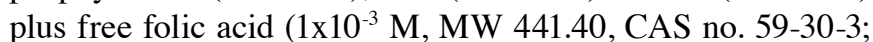
Sigma-Aldrich; Merck KGaA), and the cells were incubated for $3 \mathrm{~h}$ at $37^{\circ} \mathrm{C}$. The cells were then washed gently three times with PBS. Fresh medium was added and the cells were allowed to grow at $37^{\circ} \mathrm{C}$ for a further $21 \mathrm{~h}$, at which time they were fixed in $4 \%$ paraformaldehyde for $15 \mathrm{~min}$ at $4^{\circ} \mathrm{C}$, nuclei were stained with 300 nM DAPI stain solution (Thermo Fisher Scientific, Inc.) for $5 \mathrm{~min}$ at room temperature, and mounted using Dako fluorescence-mounting medium (Dako; Agilent Technologies, Inc., Santa Clara, CA, USA). Images of cells were captured using a confocal laser-scanning microscope (FV1000; Olympus Corporation, Tokyo, Japan). The cells in each well were detected by open field imaging under a 60x oil-immersion lens, and the area of relatively high cell density in each well was selected for subsequent fluorescence microscopy. The cell number was $20-100$ in the selected $300 \times 300 \mu \mathrm{m}$ area; this variance arose from the different size and growth rates of the various cell lines. Excitation wavelengths of 405 and $633 \mathrm{~nm}$ were used to visualize DAPI and porphysome fluorescence, respectively.

In vitro dark toxicity and PDT efficacy. To evaluate the dark toxicity of non-targeted porphysomes and FPs, H2052 and AE17-sOVA cells were seeded at a concentration of $5 \times 10^{3}$ cells/well in 96-well black-walled plates (cat. no. 655946; CELLCOAT $^{\circledR}$; Greiner Bio-One GmbH, Frickenhausen, Germany) $24 \mathrm{~h}$ prior to porphysome incubation. The cells were then grouped into four incubation conditions: Normal medium only, medium containing non-targeted porphysomes $\left(5 \times 10^{-6} \mathrm{M}\right)$, medium containing FPs $\left(5 \times 10^{-6} \mathrm{M}\right)$, and medium containing FPs $\left(5 \times 10^{-6} \mathrm{M}\right)$ and free folic acid $\left(1 \times 10^{-3} \mathrm{M}\right)$. Cells were incubated for $3 \mathrm{~h}$ at $37^{\circ} \mathrm{C}$ to allow folate receptor-mediated internalization, and each well was then gently rinsed with PBS three times and incubated for a further $21 \mathrm{~h}$ in fresh medium without porphysomes. Cell viability was measured using a colorimetric proliferation assay (CellTiter96 ${ }^{\circledR}$ AQueous One Solution Cell Assay; Promega Corporation, Madison, WI, USA), according to the manufacturer's protocol. Each experiment was performed in quadruplicate. The light absorbance was measured at $630 \mathrm{~nm}$ using a $\mu$ Quant microplate reader (BioTek Instruments, Inc., Winooski, VT, USA), with absorbance at $490 \mathrm{~nm}$ serving as background, in order to determine the relative cell viability normalized to the no-porphysome control group.

To investigate the PDT efficacy of FP, in vitro treatment was conducted. The same growth and incubation conditions were used as for the aforementioned dark toxicity studies, with eight replicates of each condition. The cells were then irradiated using a $671 \mathrm{~nm}$ continuous-wave diode laser beam expanded to $6.4 \mathrm{~mm}$ diameter to fully cover each well at a power density of $50 \mathrm{~mW} / \mathrm{cm}^{2}$. Four wells in each treatment group received a light dose of $5 \mathrm{~J} / \mathrm{cm}^{2}$ and four received $10 \mathrm{~J} / \mathrm{cm}^{2}$. Immediately after the light treatment, the incubation medium was replaced with fresh medium without porphysomes. The cell viability was measured after $24 \mathrm{~h}$ using the CellTiter96 ${ }^{\circledR}$ assay as aforementioned.

In vivo mesothelioma models. The animal study was approved by the ethics committee of the University Health Network. An orthotopic mesothelioma model was established in $\mathrm{Nu} / \mathrm{nu}$ mice (female; age, 6-8 weeks; weight, 20-25 g; Taconic Biosciences, Inc. (Rensselaer, NY, USA) by first inducing general anesthesia with $2 \%$ isoflurane. Xylazine $(20 \mathrm{mg} / \mathrm{kg}) / \mathrm{ketamine}(100 \mathrm{mg} / \mathrm{kg})$ was then injected intraperitoneally $(0.1 \mathrm{ml} / 10 \mathrm{~g}$ body weight $)$ and the mouse was placed in the left lateral position. After sterilization of the chest wall with $70 \%$ isopropyl alcohol, a bolus of $10^{6}$ AE17-sOVA cells (cultured in RPMI-1640 media supplemented with $10 \%$ FBS) in $100 \mu 1$ normal saline was injected into the left pleural cavity through the intercostal space using a $27 \mathrm{G}$ needle. After stable spontaneous respiration was confirmed, the animals were returned to their cages. Tumor growth in the pleural cavity was confirmed by micro chest computed tomography (CT)-scanning at 1 week. A subcutaneous mesothelioma model was induced using the same cell line inoculated in the thigh $\left(2 \times 10^{6}\right.$ cells in $50 \mu 1$ saline $)$. The tumor growth was monitored using calipers every 2 days for $\sim 10$ days, at which time the tumor diameter was $6-7 \mathrm{~mm}$.

In vivo porphysome accumulation in tumors. Fluorescence is a useful indicator of porphysome accumulation and cellularization in vivo, as porphyrin fluorescence is highly quenched until cellular uptake. Qualitative studies were performed in ex vivo tissues from the orthotopic tumor model using a commercial fluorescence imaging system (Maestro ${ }^{\circledR}$ EX 2.10; PerkinElmer, Inc., Waltham, MA, USA) (25). Briefly, porphysomes were injected via the tail vein at $10 \mathrm{mg} / \mathrm{kg}$, based on porphyrin content. The mice were sacrificed by $\mathrm{CO}_{2}$ followed by cervical dislocation at $6 \mathrm{~h}$ post-injection, after which, the chest was opened to expose the lung and the tumors were imaged (575-605 $\mathrm{nm}$ excitation, $647 \mathrm{~nm}$ emission). The tumors were then resected under fluorescence image guidance, together with other organs (diaphragm, chest wall, heart, lung, liver, kidney, spleen, adrenal gland, small intestine and large intestine), and placed on a 24-well dish. To further compare the non-targeted porphysomes vs. FPs, tumor and normal lung tissues $(n=3)$ were snap frozen in OCT gel, cryosectioned $(5 \mu \mathrm{m})$, mounted and stained with VECTASHIELD Antifade Mounting Medium with DAPI (cat. no. H-1200; Vector Laboratories, Inc., Burlingame, CA, USA) at room temperature for $\geq 15 \mathrm{~min}$ and imaged by confocal microscopy (x60 magnification; $633 \mathrm{~nm}$ excitation for porphyrin, $408 \mathrm{~nm}$ excitation for DAPI). To quantify porphysome uptake, freshly resected tissues were weighed and homogenized in $1 \mathrm{ml}$ PBS. The tissue suspension was then lysed at room temperature by adding Triton X-100 (final concentration, 1\%) and centrifuging at $10,000 \mathrm{x}$ g for $10 \mathrm{~min}$ at room temperature (5415D Benchtop Microcentrifuge; Eppendorf North America, Hauppauge, NY, USA); Triton X-100 was used to unquench the porphysomes. The supernatant was then measured by spectrofluorimetry 
(420 nm excitation, 600-800 $\mathrm{nm}$ emission), and the percentinjected dose per gram tissue $(\% \mathrm{ID} / \mathrm{g})$ was calculated using a pyro-lipid concentration standard curve.

PDT efficacy in vivo. The PDT efficacy of FPs was investigated in the subcutaneous tumor model using three groups $(n=6 /$ group), as follows: No treatment, light only and FP-PDT at $24 \mathrm{~h}$ after i.v. injection of $10 \mathrm{mg} / \mathrm{kg}$ FPs, with the mice kept under dim ambient lighting after injection. Treatment was administered under general anesthesia (2\% isoflurane), using a $671 \mathrm{~nm}$ diode laser (DPSS; LaserGlow Technologies, Toronto, ON, Canada) at an incident power density of $100 \mathrm{~mW} / \mathrm{cm}^{2}$ over a $9 \mathrm{~mm}$ spot size for total light dose of $100 \mathrm{~J} / \mathrm{cm}^{2}$. The tumor size was then measured with calipers every 2 days to estimate the volume. Survival was measured as a function of time after treatment and the mice were euthanized when the maximum diameter of the tumor reached $15 \mathrm{~mm}$. In a separate group, the same PDT treatment was given, but the mice were sacrificed at $24 \mathrm{~h}$ to evaluate the treatment response by histology, for which tumors were harvested, fixed in $10 \%$ formaldehyde, sectioned $(8 \mu \mathrm{m})$ and stained with H\&E. H\&E staining was carried out according to standard methods at the Pathology Research Program Laboratory at University Health Network. Digital images of the stained slides were obtained under x20 magnification using a whole slide scanner (ScanScope CS, Leica Microsystems GmbH, Wetzlar, Germany) and Aperio ImageScope software (version 12.1.0.5029; Leica Microsystems $\mathrm{GmbH})$. Alternatively, sectioned tumors underwent immunohistochemistry (IHC) to detect the expression of cleaved caspase-3 (apoptosis) and Ki-67 (tumor cell proliferation).

Effects of an EGFR inhibitor on FP-PDT responses. The potential combined effect of molecular targeted therapy using an EGFR-TKI (erlotinib; Selleck Chemicals, Houston, TX, USA) and FP-PDT was evaluated in vitro and in vivo. The expression levels of EGFR in the MPM clinical samples were initially evaluated by histological subset analysis, comparing FOLR1 and EGFR. For the in vitro studies, AE17-sOVA and H2052 cells were incubated under three conditions for $3 \mathrm{~h}$ at $37^{\circ} \mathrm{C}$, as follows ( $n=16 /$ each condition): Normal medium without porphysomes; medium containing non-targeted porphysomes $\left(5 \times 10^{-6} \mathrm{M}\right)$; and medium containing FPs $\left(5 \times 10^{-6} \mathrm{M}\right)$. Each well was then rinsed gently three times with PBS. For each condition, half of the 16 wells were then incubated for $21 \mathrm{~h}$ with $5 \mu \mathrm{M}$ erlotinib dissolved in dimethyl sulfoxide (DMSO), while the other wells were treated with DMSO only. The cells were then treated with PDT at $50 \mathrm{~mW} / \mathrm{cm}^{2}$ for doses of 5 or $10 \mathrm{~J} / \mathrm{cm}^{2}$ ( $\mathrm{n}=4$ each); after $24 \mathrm{~h}$, cell viability was measured using the CellTiter96 ${ }^{\circledR}$ assay (Promega Corporation).

The in vivo efficacy of pretreatment with EGFR-TKIs on the FP-PDT response was investigated in the AE17-sOVA subcutaneous tumor model. Erlotinib $(50 \mathrm{mg} / \mathrm{kg})$ was administered daily by oral gavage using CAPTISOL ${ }^{\circledR}$ (Ligand, San Diego, CA, USA) 2 days, 1 day and $3 \mathrm{~h}$ before PDT. This dose has exhibited antitumor efficacy without toxicity in a previous study (33). Five subgroups were used: No treatment; light only; FP-PDT; erlotinib only; and erlotinib + FP-PDT. In the PDT groups, $10 \mathrm{mg} / \mathrm{kg}$ FP was injected i.v. $24 \mathrm{~h}$ before light irradiation $\left(100 \mathrm{~J} / \mathrm{cm}^{2}\right.$ at $\left.100 \mathrm{~mW} / \mathrm{cm}^{2}\right)$. After $24 \mathrm{~h}$, the tumors were excised for histological analyses, including $\mathrm{H} \& \mathrm{E}$ and immunohistochemical staining, which was conducted at UHN and the efficacy was evaluated using Aperio ScanScope system (Leica Microsystems GmbH).

IHC. FOLR1 immunostaining was performed using the catalyzed signal amplification (CSA) system, according to the manufacturer's protocol (CSA II Biotin-free Tyramide Signal Amplification system; cat. no. K1497; Dako; Agilent Technologies, Inc.). Briefly, specimens were incubated with $3 \%$ hydrogen peroxide for $5 \mathrm{~min}$ to quench endogenous peroxidase activity and were then rinsed with distilled water and washed with TBST (0.05 M Tris-HCl, $\mathrm{pH}$ 7.6, containing $0.3 \mathrm{M} \mathrm{NaCl}$ and $0.1 \%$ Tween-20) for $5 \mathrm{~min}$. The specimens were then incubated with a protein block (serum-free protein in PBS with $0.015 \mathrm{M}$ sodium azide) for $5 \mathrm{~min}$ to suppress non-specific binding. Subsequently, they were incubated overnight at $4^{\circ} \mathrm{C}$ with a primary folate receptor $\alpha$ antibody (Novocastra ${ }^{\mathrm{TM}}$; product code, NCL-L-FRalpha; Leica Microsystems $\mathrm{GmbH}$ ) at a 1:30 dilution with mixed antibody diluent (S2022 Antibody Diluent; Dako; Agilent Technologies, Inc.) and washed three times in TBST for $5 \mathrm{~min}$. Subsequently, the specimens were sequentially incubated for 15 min each with Anti-Mouse Immunoglobulin-HRP, Amplification Reagent, and Anti-Fluorescein-HRP. Each of these sequential incubations included three washing steps with TBST (5 min/wash). Colorimetric signals were localized after incubation in Liquid DAB Substrate-Chromogen for $5 \mathrm{~min}$. Aperio ScanScope system (Leica Microsystems $\mathrm{GmbH}$ ) was used for analyses.

For cleaved caspase-3, Ki-67 and EGFR staining, heatinduced epitope retrieval was conducted by microwaving the tissue sections in $10 \mathrm{mM}$ citrate buffer (pH 6.0). Endogenous peroxidase was blocked with $3 \%$ hydrogen peroxide for $5 \mathrm{~min}$ at room temperature, and $10 \%$ normal horse serum blocking solution (cat. no. S-2000; Vector Laboratories, Inc.) was then applied to block non-specific binding for $10 \mathrm{~min}$ (for EGFR staining only). Sections were then drained and incubated at room temperature with the appropriate primary antibodies, under previously optimized conditions: Cleaved caspase-3 (cat. no. 9661; Cell Signaling Technology, Inc., Danvers, MA, USA) at 1:600 dilution overnight; Ki-67 (cat. no. NB110-90592; Novus Biologicals, LLC) at 1:700 dilution for $1 \mathrm{~h}$; EGFR (cat. no. 280005 (31G7); Invitrogen; Thermo Fisher Scientific, Inc.) at 1:100 dilution for $1 \mathrm{~h}$. Subsequently, sections were incubated with biotin-labeled anti-mouse/rabbit secondary antibodies (cat. no. BA-1400, 1:50; Vector Laboratories, Inc.) for $30 \mathrm{~min}$ at room temperature and horseradish peroxidase-conjugated ultrastreptavidin labeling reagent (Empire Genomics, LLC, Buffalo, NY, USA) for $30 \mathrm{~min}$. After washing well in TBS, color development was conducted with freshly prepared DAB. The slides were then dehydrated and cover-slipped. Aperio ScanScope (Leica Microsystems $\mathrm{GmbH}$ ) was used for analyses.

For immunohistochemical analysis of Ki-67, the percentage of positively stained nuclei was calculated using commercial software (Aperio Nuclear v9; Leica Microsystems GmbH), with the manufacturer's default settings. Cleaved caspase-3 and FOLR1 expression were calculated (Aperio Positive Pixel Count v9; Leica Microsystems GmbH) with the default settings 'Positive Cell/Total Cell'. FOLR1 expression was quantified by immunohistochemical scoring, the percentage area stained at each intensity level was multiplied by the weighted intensity, 

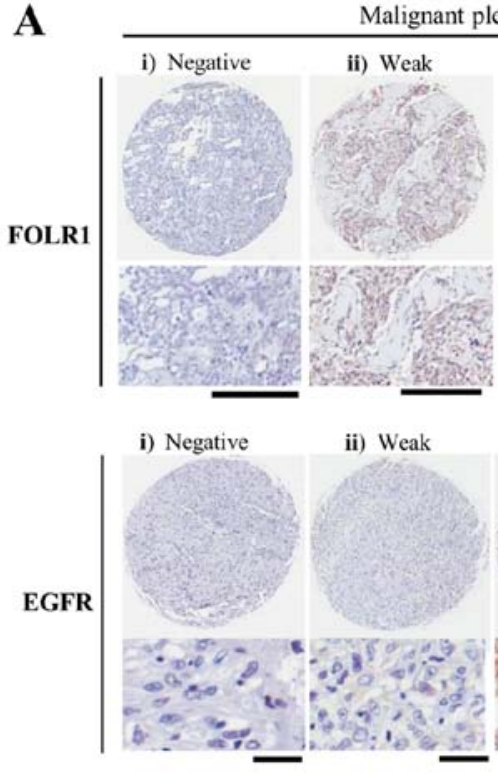

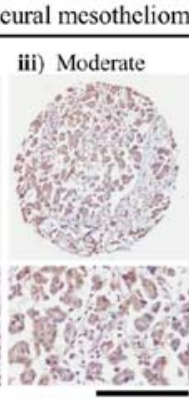

iii) Moderate

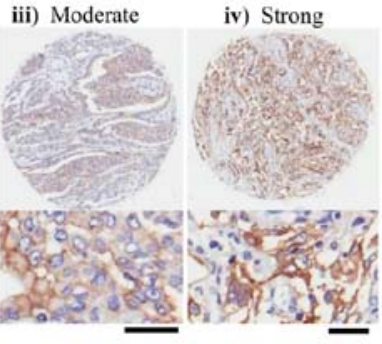

Black bar $=30 \mu \mathrm{m}$

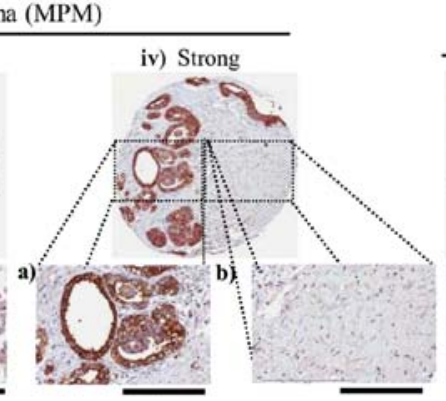

iv) Strong

B

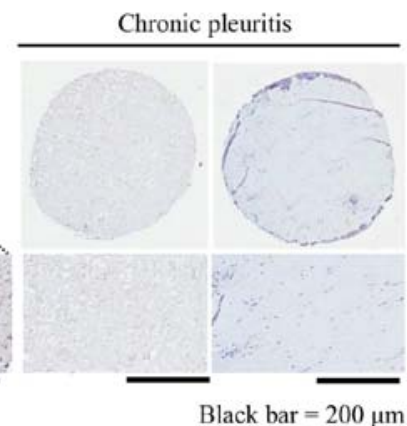

Black bar $=200 \mu \mathrm{m}$

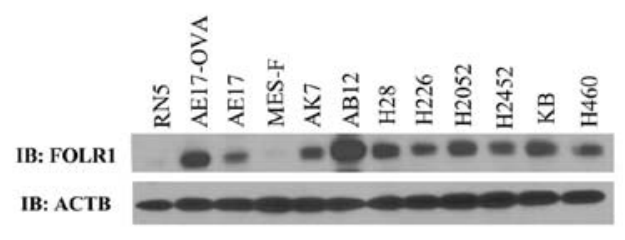

Figure 1. Expression of FOLR1 and EGFR in MPM. (A) Representative examples of FOLR1 (upper panel) and EGFR (lower panel) staining in MPM tissues on a tissue microarray. (i) Negative, (ii) weak, (iii) moderate and (iv_a) strong staining is presented. Adjacent benign pleuritis samples exhibited faint FOLR1 expression (iv_b); chronic pleuritis cases revealed almost no staining of FOLR1. (B) Western blotting of mesothelioma cell lines for the expression of FOLR1, including mouse MPM cell lines (AE17, AE17-sOVA, AK7, AB12 and RN5), human MPM cell lines (H28, H226, H2052 and H2452) and a human adult normal mesothelial cell line (MES-F). A lung large cell carcinoma (H460) and a mixed cancer type (KB) cell line were both used as positive controls, which are known to overexpress FOLR1. EGFR, epidermal growth factor receptor; FOLR1, folate receptor 1; MPM, malignant pleural mesothelioma; sOVA, secretory ovalbumin.

as reported in other studies $(47,48)$. Initially, the weighted intensity was graded as follows: Grade 0 (Negative), $1+$ (weak positive: Intensity threshold weak; upper limit 240, lower limit 220), 2+ (moderate positive: Intensity threshold medium; upper limit 220, lower limit 180), and 3+ (strong positive: Intensity threshold strong; upper limit 180, lower limit 0). FOLR1 expression was then divided into four groups: Negative (IHC score <0.50), weak (IHC score 0.50-0.99), moderate (IHC score 1.00-1.49) and strong (IHC score $\geq 1.50$ ). FOLR1 expression was finally judged as positive (weak, moderate and strong) or negative. For EGFR, each core was scored semi-quantitatively in tumor cells under x200 magnification; staining intensity was as follows: Grade 0 (negative), 1+ (weak positive), $2+$ (moderate positive) and $3+$ (strong positive).

Statistical analysis. Statistical analyses were performed with StatFlex version 6.0 for Windows (Artech Co., Ltd., Osaka, Japan). In vitro experiments were repeated at least four times. Multiple comparison analyses were used to determine statistical significance. One-factor analysis of variance, followed by Newman Keuls or Dunnett post hoc tests, was conducted when comparing the difference between treatment groups. The survival rate was calculated by the Kaplan-Meier method and the differences between groups were compared by the log-rank test. $\mathrm{P}<0.05$ was considered to indicate a statistically significant difference.

\section{Results}

FOLR1 and EGFR expression. Positive FOLR1 staining on tissue microarrays (TMAs) generally exhibited a membranous and cytoplasmic pattern (Fig. 1A) and was observed in 41 of 52 MPM cases (79\%) (Table II), 27 of which were epithelioid
( $82 \%$ of 33 cases), 12 were biphasic (92\% of 13 cases) and 2 were sarcomatoid ( $40 \%$ of 5 cases). Conversely, the benign pleuritis portion exhibited just faint FOLR1 expression. In addition, chronic pleuritis revealed almost no staining of FOLR1. EGFR was overexpressed in $89 \%$ of cases (91\% of epithelioid, $92 \%$ of biphasic, $60 \%$ of sarcomatoid and $100 \%$ of desmoplastic cases) (Table III and Fig. 1A). Notably, 71\% of MPM cases expressed both FOLR1 and EGFR (76\% of epithelioid and $85 \%$ of biphasic cases) (Table IV). FOLR1 was also highly expressed in the majority of the MPM cell lines (Fig. 1B). $\mathrm{H} 28, \mathrm{H} 2052, \mathrm{AB} 12$ and AE17-sOVA cell lines were selected as FOLR1-positive cell lines, and RN5 cells were selected as a FOLR1-negative cell line for subsequent porphysome uptake studies. RN5 cells are derived from sarcomatoid MPM; these findings were consistent with the TMA results, which detected low FOLR expression in sarcomatoid cases (Table II).

Cellular uptake and FP-PDT efficacy in vitro. The porphysome fluorescence is unquenched upon internalization into cells and therefore serves as a direct indicator of uptake. None of the cells lines exhibited significant fluorescence after incubation with non-targeting porphysomes (Fig. 2A). The FOLR1-positive H2052, H28, AB12 and AE17-sOVA cells exhibited high intracellular florescence following incubation with FPs, which was efficiently inhibited by excess free folic acid (Fig. 2A). No fluorescence signal was observed in the FOLR1-negative RNS cells (Fig. 2A). Together, these data demonstrated the specificity of cellular targeting of FPs mediated by FOLR1. The pattern of enhanced intracellular uptake with FOLR1 targeting was similar to what we previously detected in other FOLR1-positive cell lines, including KB cells (25). Fluorescence was only detected in the cytoplasm, particularly in the lysosomes (23), with no significant nuclear concentration. 
Table II. Immunopositivity of FOLR1 in malignant pleural mesothelioma $(n=52)$.

\begin{tabular}{|c|c|c|c|c|c|c|}
\hline \multirow[b]{2}{*}{ Tissue type } & \multicolumn{4}{|c|}{ FOLR1 expression $(n=52)$} & \multirow[b]{2}{*}{$\begin{array}{c}\text { Total } \\
\text { (n) }\end{array}$} & \multirow[b]{2}{*}{$\begin{array}{c}\text { Percentage } \\
\text { of FOLR1- } \\
\text { positive case }\end{array}$} \\
\hline & $\begin{array}{c}\text { Negative } \\
\text { (IHC score: } \\
0.00-0.49)\end{array}$ & $\begin{array}{c}\text { Weak } \\
\text { (IHC score: } \\
0.50-0.99)\end{array}$ & $\begin{array}{c}\text { Moderate } \\
\text { (IHC score: } \\
1.00-1.49 \text { ) }\end{array}$ & $\begin{array}{c}\text { Strong } \\
\text { (IHC score: } \\
\geq 1.50)\end{array}$ & & \\
\hline Epithelioid & $6(18.2 \%)$ & $8(24.2 \%)$ & $11(33.3 \%)$ & $8(24.2 \%)$ & 33 & $81.8(27 / 33)$ \\
\hline Biphasic & $1 \quad(7.7 \%)$ & $1 \quad(7.7 \%)$ & $10(76.9 \%)$ & $1 \quad(7.7 \%)$ & 13 & $92.3(12 / 13)$ \\
\hline Sarcomatoid & $3(60.0 \%)$ & $0 \quad(0 \%)$ & $1(20.0 \%)$ & $1(20.0 \%)$ & 5 & $40.0(2 / 5)$ \\
\hline Desmoplastic & $1(100.0 \%)$ & $0 \quad(0 \%)$ & $0 \quad(0 \%)$ & $0 \quad(0 \%)$ & 1 & $0.0(0 / 1)$ \\
\hline Total & $11(21.2 \%)$ & $9(17.3 \%)$ & $22(42.3 \%)$ & $10(19.2 \%)$ & 52 & $78.8(41 / 52)$ \\
\hline
\end{tabular}

FOLR1, folate receptor 1; IHC, immunohistochemistry.

Table III. Immunopositivity of EGFR in malignant pleural mesothelioma $(n=52)$.

\begin{tabular}{|c|c|c|c|c|c|c|}
\hline \multirow[b]{2}{*}{ Tissue type } & \multicolumn{4}{|c|}{ EGFR expression $(n=52)$} & \multirow[b]{2}{*}{ Total (n) } & \multirow[b]{2}{*}{$\begin{array}{c}\text { Percentage of EGFR- } \\
\text { positive case }\end{array}$} \\
\hline & Negative (-) & Weak (+) & Moderate $(++)$ & Strong $(+++)$ & & \\
\hline Epithelioid & $3 \quad(9.1 \%)$ & $8(24.2 \%)$ & $10(30.3 \%)$ & $12(36.4 \%)$ & 33 & $90.9(30 / 33)$ \\
\hline Biphasic & $1 \quad(7.7 \%)$ & $4(30.8 \%)$ & $3(23.1 \%)$ & $5(38.5 \%)$ & 13 & $92.3(12 / 13)$ \\
\hline Sarcomatoid & $2(40.0 \%)$ & $2(40.0 \%)$ & $1(20.0 \%)$ & $0 \quad(0.0 \%)$ & 5 & $60.0 \quad(3 / 5)$ \\
\hline Desmoplastic & $0(100.0 \%)$ & $0 \quad(0 \%)$ & $1(0 \%)$ & $0 \quad(0 \%)$ & 1 & $100.0 \quad(1 / 1)$ \\
\hline Total & $6(11.5 \%)$ & $14(26.9 \%)$ & $15(28.8 \%)$ & $17(32.7 \%)$ & 52 & $88.5(46 / 52)$ \\
\hline
\end{tabular}

EGFR, epidermal growth factor receptor; IHC, immunohistochemistry.

Table IV. Coexpression of EGFR and FOLR1 in malignant pleural mesothelioma $(\mathrm{n}=52)$.

\begin{tabular}{|c|c|c|c|c|c|c|}
\hline \multirow[b]{2}{*}{ Tissue type } & \multicolumn{5}{|c|}{ FOLR1/EGFR expression $(n=52)$} & \multirow[b]{2}{*}{$\begin{array}{l}\text { Percentage of FOLR1 and } \\
\text { EGFR coexpression }\end{array}$} \\
\hline & $-/-$ & $-/+$ & $+/-$ & $+/+$ & Total (n) & \\
\hline Epithelioid & $1 \quad(3.0 \%)$ & $5(15.2 \%)$ & $2(6.0 \%)$ & $25(75.8 \%)$ & 33 & $75.8(25 / 33)$ \\
\hline Biphasic & $0 \quad(0 \%)$ & $1 \quad(7.7 \%)$ & $1 \quad(7.7 \%)$ & $11(84.6 \%)$ & 13 & $84.6(11 / 13)$ \\
\hline Sarcomatoid & $1(20.0 \%)$ & $2(40.0 \%)$ & $1(20.0 \%)$ & $1(20.0 \%)$ & 5 & $20.0 \quad(1 / 5)$ \\
\hline Desmoplastic & $0 \quad(0 \%)$ & $1(100 \%)$ & $0(0 \%)$ & $0 \quad(0 \%)$ & 1 & $0.0 \quad(0 / 1)$ \\
\hline Total & $2(3.8 \%)$ & $9(17.3 \%)$ & $4 \quad(7.7 \%)$ & $37(71.2 \%)$ & 52 & $71.2(37 / 52)$ \\
\hline
\end{tabular}

EGFR, epidermal growth factor receptor;FOLR1, folate receptor 1; IHC, immunohistochemistry.

Cell viability of FOLR1-positive H2052 and AE17-sOVA cells was measured with or without light irradiation, in order to verify the in vitro FP-PDT efficacy (Fig. 2B). H2052 and AE17-sOVA cells treated with non-targeted porphysomes were used as a negative control. Neither non-targeted porphysomes nor FP had measurable dark toxicity at the maximum porphyrin concentration of $5 \times 10^{-6} \mathrm{M}$ in RPMI-1640 medium (Fig. 2B). However, 5 and $10 \mathrm{~J} \mathrm{~cm}^{-2}$ FP incubation plus light irradiation (after $24 \mathrm{~h}$ reduced cell viability to $57.9 \pm 2.9$ and
$48.1 \pm 3.1 \%$ in $\mathrm{H} 2052$ cells and $37.7 \pm 4.9$ and $28.9 \pm 2.6 \%$ in AE17sOVA cells, respectively (Fig. 2B). Conversely, the cytotoxicity was completely inhibited by free folic acid, and there was no measurable phototoxicity with non-targeted porphysomes.

Tumor uptake and FP-PDT efficacy in vivo. In vivo fluorescence imaging in the pleural dissemination model was conducted after chest CT confirmation of tumor development. Both non-targeted porphysomes and FPs exhibited 
A

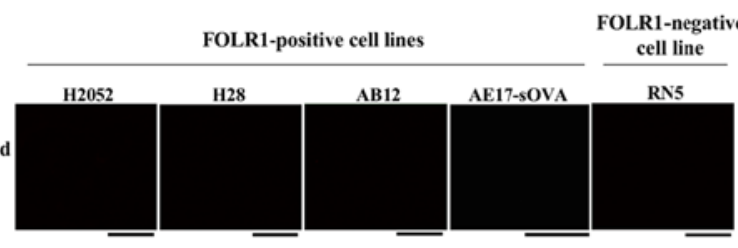

ii) Folate-
porphysome

iii) Folate-

porphysome

Free folic acid

(Inhibitor)
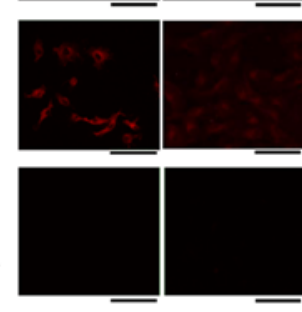

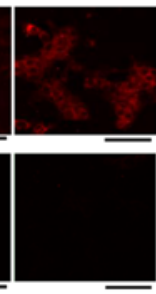

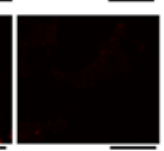

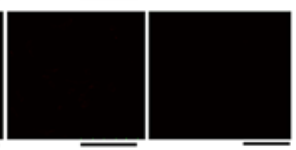

Black bar $=100 \mu \mathrm{m}$

B
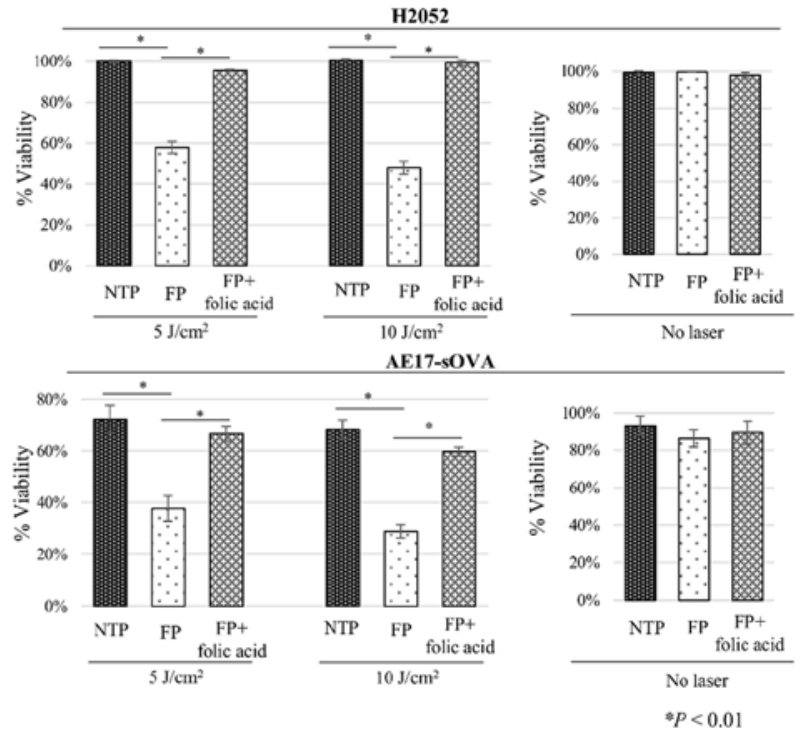

Figure 2. In vitro cellular uptake and intracellular fluorescence activation of FPs. (A) Confocal fluorescence imaging of the selected MPM cells with positive- or negative-FOLR1 expression at $21 \mathrm{~h}$ after 3-h treatment incubation. Scale bar, $100 \mu \mathrm{m}$. (B) Photodynamic therapy efficacy and dark toxicity of FP on two FOLR1-positive cell lines (H2052 and AE17-sOVA). Results are presented as the means \pm standard error of the mean (bars) of four individual wells. Cell viability was normalized to that of untreated cells, and the viability of cells was compared between the NTP group and the FP group, and between the FP group and the inhibition group. One-factor analysis of variance and a multiple comparisons test was used to evaluate the significance of differences between two groups. "P<0.05. FPs, folate-porphysomes; MPM, malignant pleural mesothelioma; NTP, non-targeted porphysome; sOVA, secretory ovalbumin.

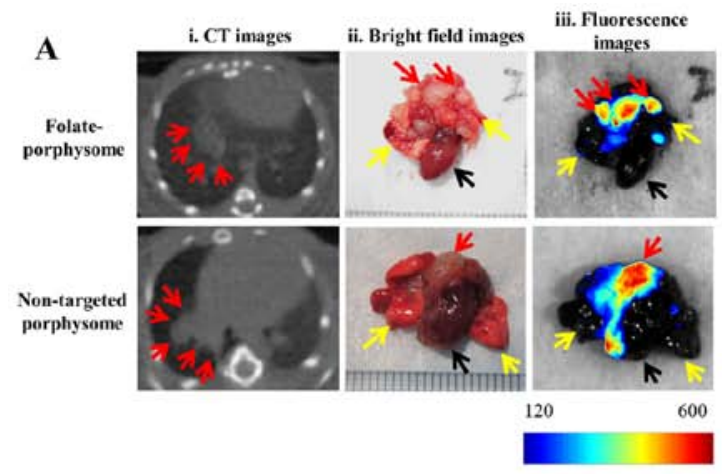

B

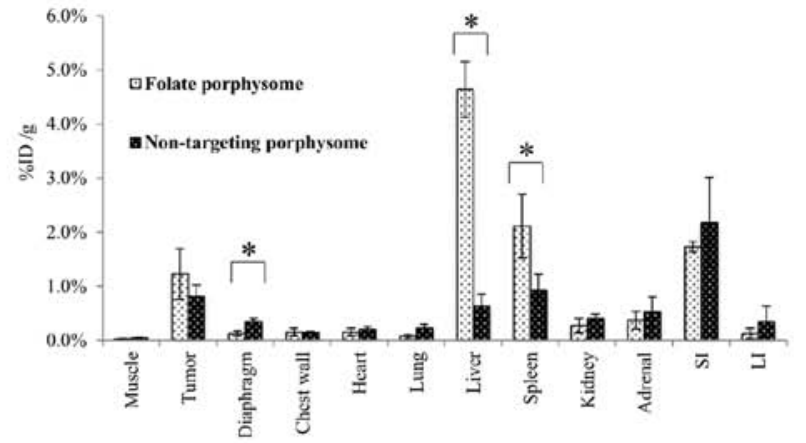

C
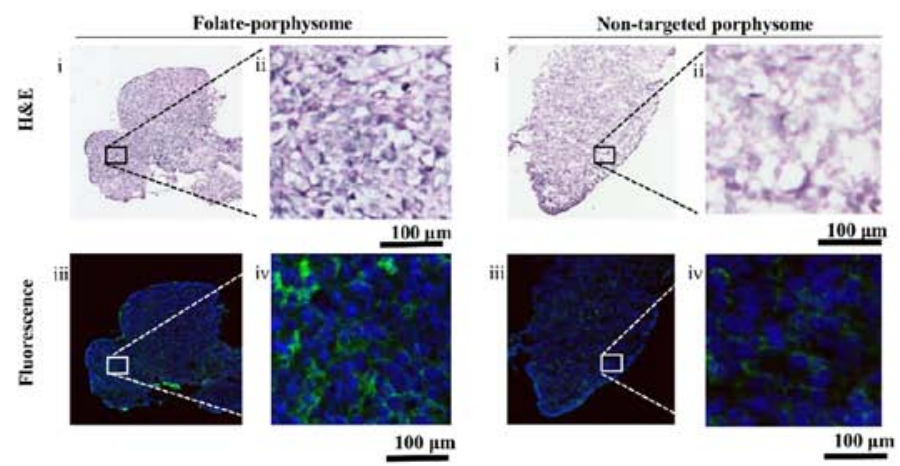

Figure 3. In vivo fluorescence activation and biodistribution of porphysomes in nude mice with disseminated intrapleural AE17-sOVA tumors. (A) (i) Representative chest CT, and (ii) bright field and (iii) Maestro ${ }^{\circledast}$ fluorescence images of the heart (black arrow), lungs (yellow arrows) and tumor nodules (red arrows) $6 \mathrm{~h}$ post-injection of FP or non-targeted porphysome $(10 \mathrm{mg} / \mathrm{kg}$ ). (B) Accumulation of FP and non-targeted porphysome in organs harvested $6 \mathrm{~h}$ after administration in mice with disseminated pleural mesothelioma. " $\mathrm{P}<0.05$. (C) Histological analysis and confocal fluorescence microscopy images of AE17-sOVA cells: (i and ii) H\&E staining, and (iii and iv) fluorescence images showing the cytoplasmic distribution (blue, DAPI at $408 \mathrm{~nm}$ excitation; green, pyro signal at $635 \mathrm{~nm}$ excitation). Scale bar represents $100 \mu \mathrm{m}$. CT, computed tomography; FP, folate-porphysome; H\&E, hematoxylin and eosin; ID/g, injected dose per gram of tissue; sOVA, secretory ovalbumin.

fluorescence activation in the tumor at $6 \mathrm{~h}$ post i.v. injection (Fig. 3A); FP-treated mice exhibited clear fluorescence of small nodules on the surface of the lungs, allowing surgical resection under image guidance (data not shown). Since 
$\mathbf{A}$

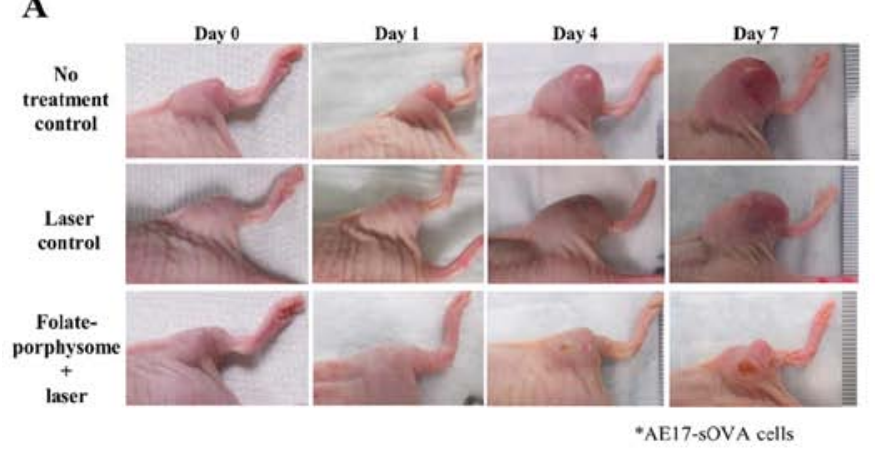

B

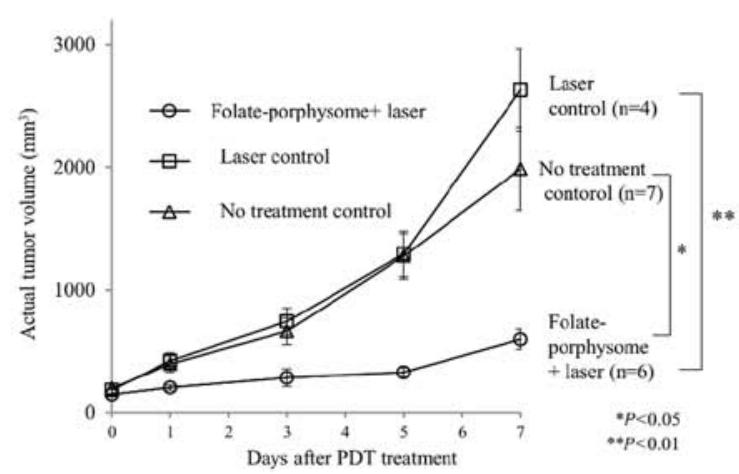

C

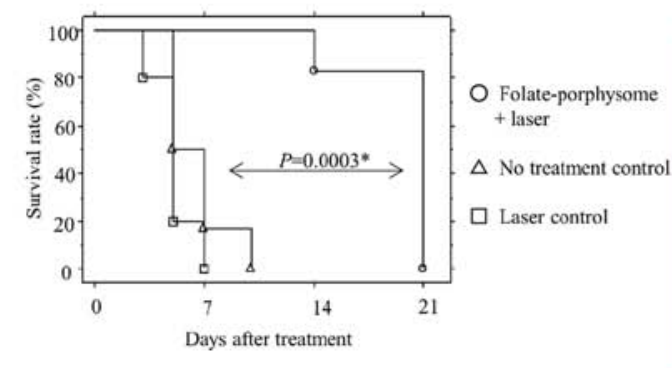

D

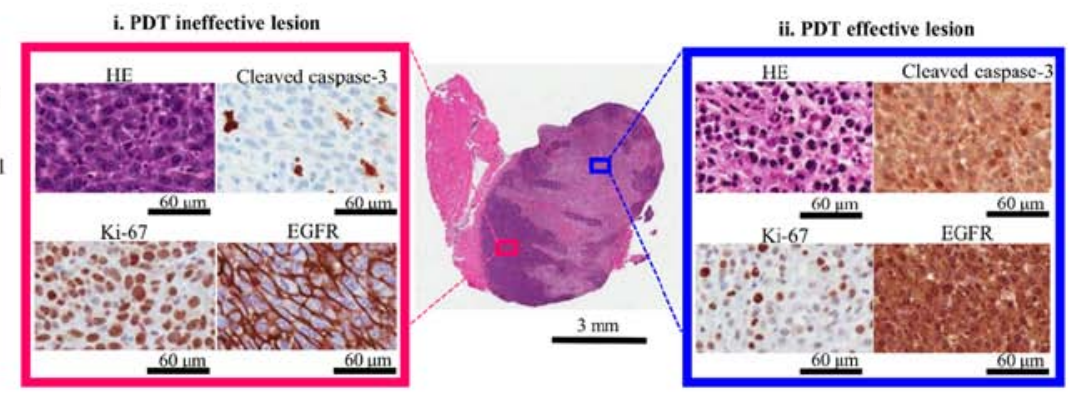

Figure 4. Post-PDT response in AE17-sOVA tumor-bearing mice. (A) Representative tumor images on days 0, 1, 4 and 7 post-PDT treatment. (B) Tumor growth curve following treatment for each group. Tumor volume in the FP-PDT group at each time-point was separately compared to each of the control groups. Statistical comparison at each time-point between groups was made by one-factor repeated measures analysis of variance and Newman-Keuls post hoc test was used to evaluate the significance of the differences between two groups on day 7 . ${ }^{*} \mathrm{P}<0.05,{ }^{* *} \mathrm{P}<0.01$. (C) Survival rate of animals in each group: Laser control $(n=5)$, no treatment control $(n=6)$, and FP + laser $(n=6)$. Survival rate of the FP-PDT group was compared with the no treatment control and the laser control groups; rates were calculated by the Kaplan-Meier method and differences between the no treatment control group and the FP-PDT group was compared using the log-rank test $(\mathrm{P}=0.0003)$. (D) Representative immunohistochemical staining images of tumors treated with FP-enabled PDT, showing (i) a PDT ineffective lesion (red box) and (ii) a PDT effective lesion (blue box). HE, cleaved caspase-3, Ki-67 and EGFR staining are presented. ANOVA, analysis of variance; EGFR, epidermal growth factor receptor; FP, folate-porphysome; H\&E, hematoxylin and eosin; PDT, photodynamic therapy; sOVA, secretory ovalbumin.

porphysome fluorescence was only partially unquenched, fluorescence imaging yielded only the relative uptake between the targeted and untargeted nanoparticles. Both showed high uptake in tumor $(1.22 \pm 0.47$ vs. $0.82 \pm 0.20 \% \mathrm{ID} / \mathrm{g})$, and the difference was not statistically significant $(\mathrm{P}=0.11)$. Conversely, there was a significant increase in FP uptake in the liver $(4.6 \pm 0.5$ vs. $0.63 \pm 0.23 \% \mathrm{ID} / \mathrm{g})$ and the spleen $(2.11 \pm 0.59$ vs. $0.92 \pm 0.29 \% \mathrm{ID} / \mathrm{g}$ ) at the same time-point (Fig. 3B). Porphysome fluorescence was clearly visible under confocal microscopy of tumor sections in the tumor cell cytoplasm (Fig. 3C).

The in vivo PDT response was assessed in AE17-sOVA subcutaneous tumors, compared with the growth of untreated tumors (Fig. 4A and B), which reached the defined endpoint of $15 \mathrm{~mm}$ diameter after 5 days. All mice were sacrificed by day 10 post-treatment (Fig. 4C). In a second control group that received laser treatment only, the same growth trend was observed as in the untreated controls, reaching the endpoint on or before day 7 (Fig. 4A-C). Conversely, FP-PDT caused typical initial tumor swelling at day 1 post-treatment $(49,50)$, which resolved by day 2, with subsequent inhibition of tumor growth (Fig. 4A and B). However, tumor regrowth was then observed at 7 days post-treatment for all mice in this group (Fig. 4B), with one mouse reaching the endpoint at day 14 and the other five on day 21 (Fig. 4C). There were no behavioral changes or local toxicities, such as skin necrosis. Therefore, FP-PDT at these photosensitizer and light doses did not completely eliminate the tumor, but significantly suppressed tumor growth and prolonged survival up to 3 weeks post-treatment.

In a previous study, FP-PDT was revealed to achieve complete tumor elimination using optimized dosing in subcutaneous KB tumors (25); therefore, optimizing the doses in the MPM model is likely to further enhance the efficacy. However, the sub-optimized FP-PDT doses allowed for investigation of the potential combined effect of EGFR inhibitor plus PDT.

Combined FP-PDT plus EGFR inhibitor. One contributor to tumor regrowth/recurrence following PDT (in general) is induced activation of cell cycle progression pathways, such as EGFR (51). Benzoporphyrin derivative-mediated PDT stimulates EGFR tyrosine phosphorylation and nuclear translocation from the cellular membrane, whereas EGFR inhibition by erlotinib results in a reduction of PDT-mediated EGFR activation $(29,52)$. In the MPM in vivo model, IHC demonstrated that EGFR was markedly activated in the region of effective FP-PDT (Fig. 4D, blue box), with nuclear translocation of EGFR from the cell membrane detected alongside a decrease in $\mathrm{Ki}-67$ positivity and an increase in the cleaved caspase-3 apoptotic index. In addition, these effects were intratumorally heterogeneous, with some regions showing viable tumor cells, higher Ki-67 positivity, and reduced apoptotic index and 


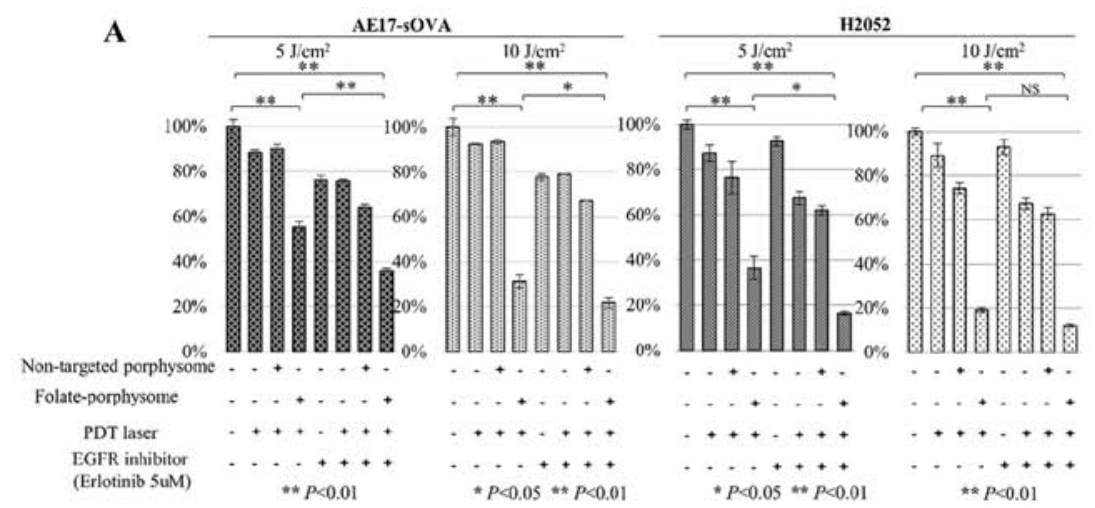

C

B
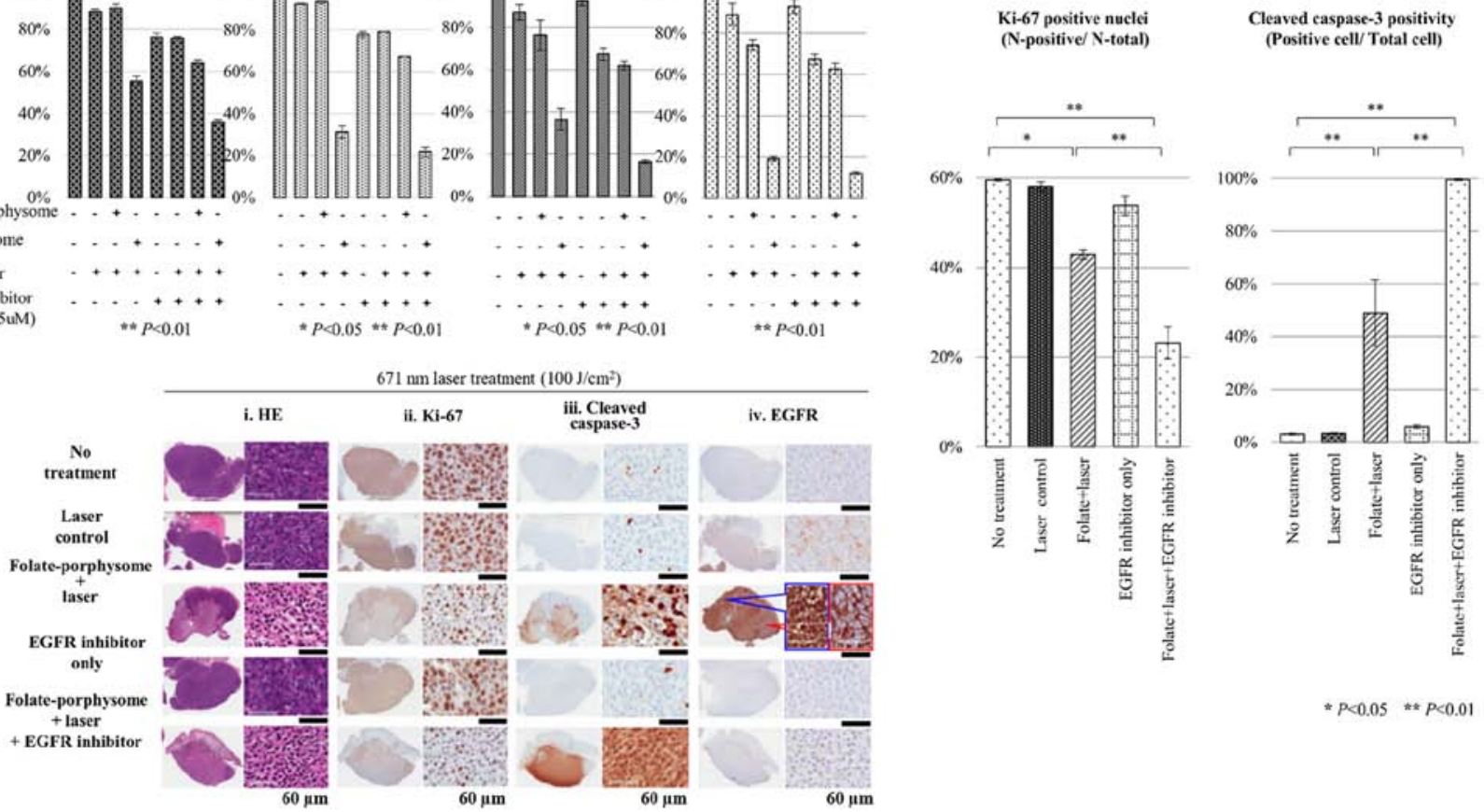

Figure 5. In vitro and in vivo evaluation of the combined therapeutic efficacy of EGFR inhibitor plus FP-enabled PDT in malignant pleural mesothelioma. (A) In vitro cytotoxicity induced by eight treatments, tested on AE17-sOVA and H2052 cell lines (both EGFR-positive and FOLR1-positive); two PDT doses $\left(5\right.$ and $\left.10 \mathrm{~J} / \mathrm{cm}^{2}\right)$ were compared. One-factor analysis of variance and a Newman-Keuls test was conducted to evaluate the significance of differences between the groups. (B) Histopathological analysis of tumors $24 \mathrm{~h}$ post-treatment, including: i) H\&E; ii) Ki-67; iii) cleaved caspase-3; and iv) EGFR staining. Black scale bar, $60 \mu \mathrm{m}$. (C) Quantitative evaluation of Ki-67 and cleaved caspase-3 staining, showing the percentage of positively stained cells in tumors from the different treatment groups. Each treatment group was compared with the control group (no treatment) using one-factor analysis of variance and Dunnett post hoc test. ${ }^{*} \mathrm{P}<0.05,{ }^{* *} \mathrm{P}<0.01$. EGFR, epidermal growth factor receptor; FP, folate-porphysome; H\&E, hematoxylin and eosin; PDT, photodynamic therapy; sOVA, secretory ovalbumin.

membranous EGFR staining; these regions appeared to be located where PDT was ineffective (Fig. 4D, red box).

In order to investigate whether inhibiting PDT-dependent EGFR signaling may increase direct cell cytotoxicity, cells in vitro were pretreated with an EGFR-TKI (erlotinib, $5 \mu \mathrm{M})$ and cell viability was measured following FP-PDT $\left(5\right.$ or $\left.10 \mathrm{~J} / \mathrm{cm}^{2}\right)$. The combination decreased the viability of AE17-sOVA cells (from 55.2 \pm 2.4 and $31.2 \pm 2.9 \%$ with FP-PDT only to $36.1 \pm 0.9$ and $21.7 \pm 2.4$ with FP-PDT plus EGFR-TKI for 5 and $10 \mathrm{~J} / \mathrm{cm}^{2}, \mathrm{P}<0.01$ and $\mathrm{P}<0.05$, respectively) and of H2052 cells (from $36.5 \pm 5.1$ to $16.4 \pm 0.8 \%$ with FP-PDT only for $5 \mathrm{~J} / \mathrm{cm}^{2}, \mathrm{P}<0.05$ ). In addition, there was a slight decrease in the viability of $\mathrm{H} 2052$ cells treated with FP-PDT $\left(10 \mathrm{~J} / \mathrm{cm}^{2}\right)$ and EGFR-TKI, as compared with cells treated with FP-PDT only, even though there was no statistical significance (from $19.0 \pm 1.1$ to $12.1 \pm 0.7 \%$; Fig. $5 \mathrm{~A}$ ).

For corresponding in vivo studies, histology was used to evaluate therapeutic efficacy. Erlotinib was administered orally at a dose of $50 \mathrm{mg} / \mathrm{kg}$ to mice bearing AE17-sOVA subcutaneous tumors 2 days, 1 day and $3 \mathrm{~h}$ before PDT treatment. Mice were sacrificed after $24 \mathrm{~h}$ for H\&E and immunohistochemical analyses (Fig. 5B). EGFR activation was completely inhibited by erlotinib (Fig. 5B). As expected, the control groups (no treatment, laser only and erlotinib only groups) exhibited $59.5 \pm 0.2,58.0 \pm 1.0$ and $53.8 \pm 2.2 \%$ positive

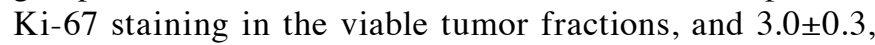

$3.3 \pm 0.2$ and $5.7 \pm 0.6 \%$ damage, as indicated by positive cleaved caspase- 3 staining (Fig. 5B and C). These findings indicated that the tumors in the control groups were minimally affected. Conversely, in the FP-PDT group, a decrease in cell viability $(42.9 \pm 1.0 \%)$ was detected by Ki- 67 staining $(\mathrm{P}<0.05$ compared with the control groups; Fig. 5B and $\mathrm{C}$ ) and significant apoptosis was observed, as determined by $48.9 \pm 12.6 \%$ positive staining of cleaved caspase- $3(\mathrm{P}<0.01$ compared with the control groups; Fig. 5B and C). However, tumors treated with FP-PDT still exhibited high EGFR activation and partial nuclear translocation (Fig. 5B), compared with the control groups. Since nuclear translocation of EGFR is thought to mediate anti-apoptotic signaling (29), these results suggested that FP-PDT initiated nuclear signaling of EGFR, which resulted in reduced PDT cytotoxicity. However, the combination of pretreatment with an EGFR inhibitor and FP-PDT further decreased Ki-67 positivity compared with in the FP-PDT groups $(23.2 \pm 3.6 \%, \mathrm{P}<0.01)$, and much higher cleaved caspase- 3 positivity, and thus apoptosis, was also detected $(99.5 \pm 0.2 \%, \mathrm{P}<0.01)$.

\section{Discussion}

Mesothelioma is associated with a very poor prognosis, due to the late onset of clinical symptoms that delay diagnosis and limit therapeutic options (53). Surgical treatment is 
most efficient when the tumor is of epithelioid subtype and essentially confined to the hemithorax without lymph node metastasis at the time of diagnosis (54). The addition of localized PDT has been reported to limit the rate of tumor growth after recurrence following EPD surgery $(14,15)$ and technical advances have improved the uniformity of light delivery, including the use of a light-scattering medium to fill the pleural cavity $(18,55)$. We aim to focus on the use of an optimal light-scattering medium within the pleural cavity in the future. The relatively poor tumor specificity of current approved photosensitizers remains a major challenge to achieve safe and effective PDT treatment. Therefore, the present study introduced a novel tumorspecific nanostructure-based photosensitizer to enhance PDT efficacy and tumor selectivity, and evaluated the effects of pretreatment with an EGFR inhibitor. Firstly, IHC staining of TMA samples and western blot analysis of cell lysates demonstrated that FOLR1 was highly expressed in MPM, which is in line with a previous study, in which $72 \%$ of MPM cases had a 2- to 4 -fold increase in FOLR1 mRNA expression compared with in normal tissues; in addition, IHC detected FOLR1 expression on the cellular membrane in 13 of 17 frozen samples (26). Likely as a consequence of this, FPs exhibited markedly higher cellular uptake compared with non-targeted porphysomes in vitro, and possessed higher photocytotoxicity in FOLR1-positive MPM cell lines. FPs have a shorter circulation half-life than non-targeted porphysome in vivo (3.5 vs. $10.4 \mathrm{~h})$; therefore, a $6 \mathrm{~h}$ FP-light interval was used as the optimal interval in a previous FP-PDT study in FOLR1-positive KB tumors (25). The present study also compared the biodistribution of FPs and non-targeted porphysomes at this time-point. As expected, significantly more FPs, compared with non-targeted porphysomes, accumulated in the liver and spleen, which was probably due to the extended retention of FPs in these two organs caused by receptormediated endocytosis, whereas non-targeting porphysomes were cleared out more quickly by the reticulo-endothelial system (56). However, the uptake in FOLR1-positive tumors was not statistically different, likely since both are mediated by the EPR effect due to their nano-scale size (57). Notably, however, only FPs were internalized into the FOLR1positive tumor cells and became reactivated for PDT upon disruption of the nanostructure, whereas non-targeted porphysomes remained in the interstitial space and most of them remained photodynamically quenched (25). The therapeutic efficacy and mechanism of FPs were investigated previously (25). FPs are unquenched inside targeted cells, and porphyrins, as PDT agents, are activated to generate singlet oxygen for Type II PDT reactions upon irradiation of the PDT laser. Consequently, significant FP-PDT efficacy has been observed. This MPM tumor-specific PDT efficacy may translate into a wider therapeutic window for treating disseminated MPM in the pleural cavity and may avoid the dose-limiting normal tissue phototoxicity of conventional photosensitizers. Since FOLR1 is overexpressed in several tumors, including adenocarcinoma of the ovary, uterus and the pituitary gland, testicular choriocarcinoma and ependymal brain tumor $(26,58-63)$, the technology should be more widely applicable.
Although tumor growth in vivo was significantly suppressed by FP-PDT, the tumor recurred and all mice eventually reached the endpoint by 21 days after treatment. This may be caused in part by heterogeneous FP distribution in the tumor (64) and, as indicated by the heterogeneous distribution of residual viable tumor cells in regions of EGFR overexpression, by activation of survival pathways and nuclear translocation. Since it has been reported that inhibiting EGFR signaling increases PDT cytotoxicity through a mechanism that involves increased apoptotic cell death (29), the present study investigated this as a strategy to improve FP-PDT. The human-TMA analysis revealed $\sim 89 \%$ EGFR positivity and, more importantly, $\sim 70 \%$ coexpression of FOLR1 and EGFR in MPM. In the present study, erlotinib pretreatment synergistically enhanced the efficacy of FP-PDT, which was associated with reduced EGFR activation, decreased expression of the cell proliferation marker Ki-67 and increased apoptosis, as determined by cleaved caspase-3 positivity. Numerous mechanisms may be involved here, including erlotinib-induced increase of photosensitizer accumulation and/or sensitization of the tumor vasculature (33). While this enhanced response was measured only by histological analysis, these findings suggested that further preclinical and clinical development of this strategy may be beneficial.

Finally, the formulation of porphysomes can be modified easily due to their liposomal structure (23). Therefore, other targeting motifs, such as prostate specific membrane antigen and EGFR, could be integrated into the porphysome formulation to target other tumor types. Porphyrins are also natural metal chelators and we previously developed ${ }^{64} \mathrm{Cu}$ folate-porphysomes as a radioactive tracer for positron emission tomography imaging (65), in order to detect tumors at different stages, assist in pretreatment planning, provide real-time guidance for surgical navigation, or to monitor posttreatment tumor responses. FP-PDT could also be combined with other therapies, for example by loading the porphysome core or lipid bilayer with chemotherapeutic drugs, such as doxorubicin, for more targeted tumor delivery (23).

In conclusion, the present study demonstrated the efficacy of FP-enabled PDT for the treatment of FOLR1positive MPM in preclinical models in vitro and in vivo, as well as the combined therapeutic effect of pretreatment with EGFR-TKI. If clinically translatable, this should improve the efficacy and safety of intrapleural PDT as an adjuvant treatment that could improve the prognosis of this highly fatal disease.

\section{Acknowledgements}

The authors would like to thank Mr. Takatomo Funayama (Morphotechnology Co., Ltd., Sapporo, Japan) who conducted FOLR1 and EGFR immunohistochemical studies; Ms. Melanie Peralta (Pathology Research Program Laboratory at University Health Network, Toronto, ON, Canada) who performed Ki-67, cleaved caspase-3 and EGFR immunohistochemical studies; and Ms. Judy McConnell, Ms. Alexandria Grindlay and Ms. Kimberley Hudson (Toronto General Hospital, Toronto, ON, Canada) for laboratory management. 


\section{Funding}

No funding was received.

\section{Availability of data and materials}

All data generated or analyzed during this study are included in this published article.

\section{Authors' contributions}

TK and CSJ performed the experimental design, most of the experiments and analysis, drafted the manuscript, and were involved in the conception and design of the study. TK was also involved in collecting clinical tissue samples and accessing clinical databases. DL conducted experiments, analyzed the data, performed the statistical analysis and contributed to the writing of the manuscript. HU, KF, HPH, HW and LW conducted some supporting in vivo experiments. $\mathrm{HK}, \mathrm{YH}$, and $\mathrm{KCH}$ contributed to the preparation and the review of the tissue microarray. RAW performed some supporting laser experiments. JC, KK, YM, MDP, BCW, GZ and KY supervised the study, were involved in the conception and design of the study, and proofread the manuscript. YM participated in the planning/design of the tissue microarray experiments and supervised the pathological review. All authors have read and approved the final manuscript.

\section{Ethics approval and consent to participate}

The protocol was approved by the appropriate institutional review board of Hokkaido University [approval no. 012-0136]. Each patient provided written informed consent at the time of surgery. The animal study was approved by the ethics committee of University Health Network.

\section{Patient consent for publication}

Not applicable.

\section{Competing interests}

The authors declare that they have no competing interests.

\section{References}

1. Yang H, Testa JR and Carbone M: Mesothelioma epidemiology, carcinogenesis, and pathogenesis. Curr Treat Options Oncol 9: 147-157, 2008.

2. Kotova S, Wong RM and Cameron RB: New and emerging therapeutic options for malignant pleural mesothelioma: Review of early clinical trials. Cancer Manag Res 7: 51-63, 2015.

3. Robinson BM: Malignant pleural mesothelioma: An epidemiological perspective. Ann Cardiothorac Surg 1: 491-496, 2012.

4. Robinson BW and Lake RA: Advances in malignant mesothelioma. N Engl J Med 353: 1591-1603, 2005.

5. Becklake MR, Bagatin E and Neder JA: Asbestos-related diseases of the lungs and pleura: Uses, trends and management over the last century. Int J Tuberc Lung Dis 11: 356-369, 2007.

6. Scherpereel A, Astoul P, Baas P, Berghmans T, Clayson $\mathrm{H}$, de Vuyst P, Dienemann H, Galateau-Salle F, Hennequin C, Hillerdal G, et al; European Respiratory Society/European Society of Thoracic Surgeons Task Force: Guidelines of the European Respiratory Society and the European Society of Thoracic Surgeons for the management of malignant pleural mesothelioma. Eur Respir J 35: 479-495, 2010.
7. Flores RM, Pass HI, Seshan VE, Dycoco J, Zakowski M, Carbone M, Bains MS, Rusch VW: Extrapleural pneumonectomy versus pleurectomy/decortication in the surgical management of malignant pleural mesothelioma: results in 663 patients. J Thorac Cardiovasc Surg 135: 620-626, 626 e621-623, 2008.

8. Kostron A, Friess M, Crameri O, Inci I, Schneiter D, Hillinger S, Stahel R, Weder W and Opitz I: Relapse pattern and secondline treatment following multimodality treatment for malignant pleural mesothelioma. Eur J Cardiothorac Surg 49: 1516-1523, 2016.

9. Baldini EH, Richards WG, Gill RR, Goodman BM, Winfrey OK, Eisen HM, Mak RH, Chen AB, Kozono DE, Bueno R, et al: Updated patterns of failure after multimodality therapy for malignant pleural mesothelioma. J Thorac Cardiovasc Surg 149: 1374-1381,2015.

10. Gomez DR, Hong DS, Allen PK, Welsh JS, Mehran RJ, Tsao AS, Liao Z, Bilton SD, Komaki R and Rice DC: Patterns of failure, toxicity, and survival after extrapleural pneumonectomy and hemithoracic intensity-modulated radiation therapy for malignant pleural mesothelioma. J Thorac Oncol 8: 238-245, 2013.

11. Gupta V, Krug LM, Laser B, Hudka K, Flores R, Rusch VW and Rosenzweig KE: Patterns of local and nodal failure in malignant pleural mesothelioma after extrapleural pneumonectomy and photon-electron radiotherapy. J Thorac Oncol 4: 746-750, 2009.

12. Tsao AS, Mehran R and Roth JA: Neoadjuvant and intrapleural therapies for malignant pleural mesothelioma. Clin Lung Cancer 10: 36-41, 2009.

13. Sterman DH, Alley E, Stevenson JP, Friedberg J, Metzger S, Recio A, Moon EK, Haas AR, Vachani A, Katz SI, et al: Pilot and feasibility trial evaluating immuno-gene therapy of malignant mesothelioma using intrapleural delivery of adenovirus-IFN $\alpha$ combined with chemotherapy. Clin Cancer Res 22: 3791-3800, 2016.

14. Friedberg JS, Culligan MJ, Mick R,, Stevenson J, Hahn SM, Sterman D, Punekar S, Glatstein E and Cengel K: Radical pleurectomy and intraoperative photodynamic therapy for malignant pleural mesothelioma. Ann Thorac Surg 93: 1658-65; discussion 1665-7, 2012.

15. Friedberg JS: Photodynamic therapy for malignant pleural mesothelioma. J Natl Compr Canc Netw 10 (Suppl 2): S75-S79, 2012.

16. Vrouenraets MB, Visser GW, Snow GB and van Dongen GA: Basic principles, applications in oncology and improved selectivity of photodynamic therapy. Anticancer Res 23B: 505-522, 2003.

17. Dolmans DE, Fukumura D and Jain RK: Photodynamic therapy for cancer. Nat Rev Cancer 3: 380-387, 2003.

18. Pass HI, DeLaney TF, Tochner Z, Smith PE, Temeck BK, Pogrebniak HW, Kranda KC, Russo A, Friauf WS, Cole JW, et al: Intrapleural photodynamic therapy: Results of a phase I trial. Ann Surg Oncol 1: 28-37, 1994.

19. Takita H, Mang TS, Loewen GM, Antkowiak JG, Raghavan D, Grajek JR and Dougherty TJ: Operation and intracavitary photodynamic therapy for malignant pleural mesothelioma: A phase II study. Ann Thorac Surg 58: 995-998, 1994.

20. Schouwink H, Rutgers ET, van der Sijp J, Oppelaar H, van Zandwijk $N$, van Veen $R$, Burgers S, Stewart FA, Zoetmulder $\mathrm{F}$ and Baas P: Intraoperative photodynamic therapy after pleuropneumonectomy in patients with malignant pleural mesothelioma: Dose finding and toxicity results. Chest 120: 1167-1174, 2001.

21. Friedberg JS, Mick R, Stevenson J, Metz J, Zhu T, Buyske J, Sterman DH, Pass HI, Glatstein E and Hahn SM: A phase I study of Foscan-mediated photodynamic therapy and surgery in patients with mesothelioma. Ann Thorac Surg 75: 952-959, 2003.

22. Moghissi K and Dixon K: Photodynamic therapy in the management of malignant pleural mesothelioma: A review. Photodiagn Photodyn Ther 2: 135-147, 2005.

23. Lovell JF, Jin CS, Huynh E, Jin H, Kim C, Rubinstein JL, Chan WC, Cao W, Wang LV and Zheng G: Porphysome nanovesicles generated by porphyrin bilayers for use as multimodal biophotonic contrast agents. Nat Mater 10: 324-332, 2011.

24. Jin CS, Lovell JF, Chen J and Zheng G: Ablation of hypoxic tumors with dose-equivalent photothermal, but not photodynamic, therapy using a nanostructured porphyrin assembly. ACS Nano 7: 2541-2550, 2013.

25. Jin CS, Cui L, Wang F, Chen J and Zheng G: Targeting-triggered porphysome nanostructure disruption for activatable photodynamic therapy. Adv Healthc Mater 3: 1240-1249, 2014.

26. Bueno R, Appasani K, Mercer H, Lester S and Sugarbaker D: The alpha folate receptor is highly activated in malignant pleural mesothelioma. J Thorac Cardiovasc Surg 121: 225-233, 2001. 
27. Nutt JE, Razak AR, O'Toole K, Black F, Quinn AE, Calvert AH, Plummer ER and Lunec J: The role of folate receptor alpha (FRalpha) in the response of malignant pleural mesothelioma to pemetrexed-containing chemotherapy. Br J Cancer 102: 553-560, 2010.

28. Lovell JF, Liu TWB, Chen J and Zheng G: Activatable photosensitizers for imaging and therapy. Chem Rev 110: 2839-2857, 2010.

29. Edmonds C, Hagan S, Gallagher-Colombo SM, Busch TM and Cengel KA: Photodynamic therapy activated signaling from epidermal growth factor receptor and STAT3: Targeting survival pathways to increase PDT efficacy in ovarian and lung cancer. Cancer Biol Ther 13: 1463-1470, 2012.

30. Bhuvaneswari R, Yuen GY, Chee SK and Olivo $M$ : Antiangiogenesis agents avastin and erbitux enhance the efficacy of photodynamic therapy in a murine bladder tumor model. Lasers Surg Med 43: 651-662, 2011.

31. Weyergang A, Selbo PK and Berg K: Sustained ERK [corrected] inhibition by EGFR targeting therapies is a predictive factor for synergistic cytotoxicity with PDT as neoadjuvant therapy. Biochim Biophys Acta 1830: 2659-2670, 2013.

32. Bhuvaneswari R, Gan YY, Soo KC and Olivo M: Targeting EGFR with photodynamic therapy in combination with Erbitux enhances in vivo bladder tumor response. Mol Cancer 8: 94, 2009.

33. Gallagher-Colombo SM, Miller J, Cengel KA, Putt ME, Vinogradov SA and Busch TM: Erlotinib pretreatment improves photodynamic therapy of non-small cell lung carcinoma xenografts via multiple mechanisms. Cancer Res 75: 3118-3126, 2015

34. Postiglione I, Chiaviello A, Aloj SM and Palumbo G: 5-aminolaevulinic acid/photo-dynamic therapy and gefitinib in non-small cell lung cancer cell lines: A potential strategy to improve gefitinib therapeutic efficacy. Cell Prolif 46: 382-395, 2013.

35. Kurai J, Chikumi H, Hashimoto K, Takata M, Sako T, Yamaguchi K, Kinoshita N, Watanabe M, Touge H, Makino H, et al: Therapeutic antitumor efficacy of anti-epidermal growth factor receptor antibody, cetuximab, against malignant pleural mesothelioma. Int J Oncol 41: 1610-1618, 2012.

36. Destro A, Ceresoli GL, Falleni M, Zucali PA, Morenghi E, Bianchi P, Pellegrini C, Cordani N, Vaira V, Alloisio M, et al: EGFR overexpression in malignant pleural mesothelioma. An immunohistochemical and molecular study with clinico-pathological correlations. Lung Cancer 51: 207-215, 2006.

37. Garland LL, Rankin C, Gandara DR, Rivkin SE, Scott KM, Nagle RB, Klein-Szanto AJ, Testa JR, Altomare DA and Borden EC: Phase II study of erlotinib in patients with malignant pleural mesothelioma: A Southwest Oncology Group Study. J Clin Oncol 25: 2406-2413, 2007

38. Agarwal V,Lind MJ and Cawkwell L: Targeted epidermal growth factor receptor therapy in malignant pleural mesothelioma: Where do we stand? Cancer Treat Rev 37: 533-542, 2011.

39. Okuda K, Sasaki H, Kawano O, Yukiue H, Yokoyama T, Yano $\mathrm{M}$ and Fujii Y: Epidermal growth factor receptor gene mutation, amplification and protein expression in malignant pleural mesothelioma. J Cancer Res Clin Oncol 134: 1105-1111, 2008.

40. Union for International Cancer Control (UICC): TNM Classification of Malignant Tumours. 7th edition. Wiley-Blackwell, Hoboken 2009.

41. ZenBio I: Human mesothelial cells (http://www.zen-bio.com/ products/cells/mesothelial.php). Accessed July 18, 2014.

42. ExPASy: the SIB Bioinformatics Resource Portal (https://web. expasy.org/cellosaurus/CVCL 0372).

43. Jackaman C, Bundell CS, Kinnear BF, Smith AM, Filion P, van Hagen D, Robinson BW and Nelson DJ: IL-2 intratumoral immunotherapy enhances $\mathrm{CD} 8^{+} \mathrm{T}$ cells that mediate destruction of tumor cells and tumor-associated vasculature: A novel mechanism for IL-2. J Immunol 171: 5051-5063, 2003.

44. ExPASy: the SIB Bioinformatics Resource Portal_AE17-sOVA https://web.expasy.org/cellosaurus/CVCL_LJ85.

45. Cordier Kellerman L, Valeyrie L, Fernandez N, Opolon P, Sabourin JC, Maubec E, Le Roy P, Kane A, Legrand A, Abina MA, et al: Regression of AK7 malignant mesothelioma established in immunocompetent mice following intratumoral gene transfer of interferon gamma. Cancer Gene Ther 10: 481-490, 2003.
46. Blum W, Pecze L, Felley-Bosco E, Worthmüller-Rodriguez J, Wu L, Vrugt B, de Perrot M and Schwaller B: Establishment of immortalized murine mesothelial cells and a novel mesothelioma cell line. In Vitro Cell Dev Biol Anim 51: 714-721, 2015.

47. Kato T, Wada H, Patel P, Hu HP, Lee D, Ujiie H, Hirohashi K, Nakajima T, Sato M, Kaji M, et al: Overexpression of KIF23 predicts clinical outcome in primary lung cancer patients. Lung Cancer 92: 53-61, 2016.

48. Kato T, Lee D, Wu L, Patel P, Young AJ, Wada H, Hu HP, Ujiie H, Kaji M, Kano S, et al: Kinesin family members KIF11 and KIF23 as potential therapeutic targets in malignant pleural mesothelioma. Int J Oncol 49: 448-456, 2016.

49. Castano AP, Demidova TN and Hamblin MR: Mechanisms in photodynamic therapy: Part two-cellular signaling, cell metabolism and modes of cell death. Photodiagn Photodyn Ther 2: 1-23, 2005

50. Moor AC: Signaling pathways in cell death and survival after photodynamic therapy. J Photochem Photobiol B 57: 1-13, 2000.

51. Pugh CW and Ratcliffe PJ: Regulation of angiogenesis by hypoxia: Role of the HIF system. Nat Med 9: 677-684, 2003.

52. Wang SC and Hung MC: Nuclear translocation of the epidermal growth factor receptor family membrane tyrosine kinase receptors. Clin Cancer Res 15: 6484-6489, 2009.

53. Boffetta P, Donaldson K, Moolgavkar S and Mandel JS: A systematic review of occupational exposure to synthetic vitreous fibers and mesothelioma. Crit Rev Toxicol 44: 436-449, 2014.

54. Friedberg JS, Simone CB II, Culligan MJ, Barsky AR, Doucette A, McNulty S, Hahn SM, Alley E, Sterman DH, Glatstein E, et al: Extended pleurectomy-decortication-based treatment for advanced stage epithelial mesothelioma yielding a median survival of nearly three years. Ann Thorac Surg 103: 912-919, 2017.

55. Rodriguez E, Baas P and Friedberg JS: Innovative therapies: Photodynamic therapy. Thorac Surg Clin 14: 557-566, 2004.

56. Lovell JF, Jin CS, Huynh E, MacDonald TD, Cao W and Zheng G: Enzymatic regioselection for the synthesis and biodegradation of porphysome nanovesicles. Angew Chem Int Ed Engl 51: 2429-2433, 2012

57. Albanese A, Tang PS and Chan WC: The effect of nanoparticle size, shape, and surface chemistry on biological systems. Annu Rev Biomed Eng 14: 1-16, 2012.

58. Weitman SD, Weinberg AG, Coney LR, Zurawski VR, Jennings DS and Kamen BA: Cellular localization of the folate receptor: Potential role in drug toxicity and folate homeostasis. Cancer Res 52: 6708-6711, 1992 .

59. Chancy CD, Kekuda R, Huang W, Prasad PD, Kuhnel JM, Sirotnak FM, Roon P, Ganapathy V and Smith SB: Expression and differential polarization of the reduced-folate transporter-1 and the folate receptor alpha in mammalian retinal pigment epithelium. J Biol Chem 275: 20676-20684, 2000.

60. Toffoli G, Cernigoi C, Russo A, Gallo A, Bagnoli M and Boiocchi M: Overexpression of folate binding protein in ovarian cancers. Int J Cancer 74: 193-198, 1997.

61. Ross JF, Chaudhuri PK and Ratnam M: Differential regulation of folate receptor isoforms in normal and malignant tissues in vivo and in established cell lines. Physiologic and clinical implications. Cancer 73: 2432-2443, 1994.

62. Evans CO, Young AN, Brown MR, Brat DJ, Parks JS, Neish AS and Oyesiku NM: Novel patterns of gene expression in pituitary adenomas identified by complementary deoxyribonucleic acid microarrays and quantitative reverse transcription-polymerase chain reaction. J Clin Endocrinol Metab 86: 3097-3107, 2001.

63. Weitman SD, Frazier KM and Kamen BA: The folate receptor in central nervous system malignancies of childhood. J Neurooncol 21: $107-112,1994$

64. Jain RK and Stylianopoulos T: Delivering nanomedicine to solid tumors. Nat Rev Clin Oncol 7: 653-664, 2010.

65. Ni NC, Jin CS, Cui L, Shao Z, Wu J, Li SH, Weisel RD, Zheng G and Li RK: Non-invasive macrophage tracking using novel porphysome nanoparticles in the post-myocardial Infarction murine heart. Mol Imaging Biol 18: 557-568, 2016.

This work is licensed under a Creative Commons Attribution-NonCommercial-NoDerivatives 4.0 International (CC BY-NC-ND 4.0) License. 